\title{
The biological action of saponins in animal systems: a review
}

\author{
George Francis ${ }^{1}$, Zohar Kerem ${ }^{2}$, Harinder P. S. Makkar ${ }^{3}$ and Klaus Becker ${ }^{1 *}$ \\ ${ }^{1}$ Department of Aquaculture Systems and Animal Nutrition, Institute for Animal Production in the Tropics and Subtropics, \\ University of Hohenheim (480), D 70593 Stuttgart, Germany \\ ${ }^{2}$ Institute of Biochemistry, Food Science and Nutrition, Faculty of Agricultural, Food and Environmental Quality Sciences, \\ The Hebrew University of Jerusalem, P.O.B. 12, Rehovot 76100, Israel \\ ${ }^{3}$ Animal Production and Health Section, International Atomic Energy Agency, P.O. Box 100, Wagramerstr. 5, A-1400 \\ Vienna, Austria \\ (Received 4 December 2001 - Revised 19 June 2002 - Accepted 11 August 2002)
}

\begin{abstract}
Saponins are steroid or triterpenoid glycosides, common in a large number of plants and plant products that are important in human and animal nutrition. Several biological effects have been ascribed to saponins. Extensive research has been carried out into the membrane-permeabilising, immunostimulant, hypocholesterolaemic and anticarcinogenic properties of saponins and they have also been found to significantly affect growth, feed intake and reproduction in animals. These structurally diverse compounds have also been observed to kill protozoans and molluscs, to be antioxidants, to impair the digestion of protein and the uptake of vitamins and minerals in the gut, to cause hypoglycaemia, and to act as antifungal and antiviral agents. These compounds can thus affect animals in a host of different ways both positive and negative.
\end{abstract}

Saponins: Steroids: Triterpenoids: Biological activity

The saponins are naturally occurring surface-active glycosides. They are mainly produced by plants, but also by lower marine animals and some bacteria (Riguera, 1997; Yoshiki et al. 1998). They derive their name from their ability to form stable, soap-like foams in aqueous solutions. This easily observable character has attracted human interest from ancient times. Saponins consist of a sugar moiety usually containing glucose, galactose, glucuronic acid, xylose, rhamnose or methylpentose, glycosidically linked to a hydrophobic aglycone (sapogenin) which may be triterpenoid (Fig. 1(a)) or steroid (Fig. 1(b)) in nature. The aglycone may contain one or more unsaturated $\mathrm{C}-\mathrm{C}$ bonds. The oligosaccharide chain is normally attached at the $\mathrm{C}_{3}$ position (monodesmosidic), but many saponins have an additional sugar moiety at the $\mathrm{C}_{26}$ or $\mathrm{C}_{28}$ position (bidesmosidic). The great complexity of saponin structure arises from the variability of the aglycone structure, the nature of the side chains and the position of attachment of these moieties on the aglycone. Experiments demonstrating the physiological, immunological and pharmacological properties of saponins have provoked considerable clinical interest in these substances.
There have been several reviews in recent years of published reports about various properties of saponins (Kensil, 1996; Barr et al. 1998; Sen et al. 1998; Yoshiki et al. 1998). Most of them, however, deal with either specific properties or specific sources of saponins. The purpose of the present review is to provide an overview of the extremely diverse biological activities of saponins, relate these to their structure and try to understand the molecular mechanism of their activity, as far as the available literature permits. It is hoped that the information collated here will provide the reader with information regarding the various potential applications of saponins, and stimulate further research into these compounds.

\section{Occurrence}

Saponins occur constitutively in a great many plant species, in both wild plants and cultivated crops. In cultivated crops the triterpenoid saponins are generally predominant, while steroid saponins are common in plants used as herbs or for their health-promoting properties (Fenwick et al. 1991). Triterpenoid saponins have been

\footnotetext{
Abbreviations: DDMP, 2, 3-dihydro-2, 5-dihydroxy-6-methyl-4H-pyran-4-one; GJIC, gap junction-mediated intercellular communication; GR, glucocorticoid receptor; NF- $\mathrm{BB}$, nuclear transcription factor- $\mathrm{B}$; TPD, transmural potential difference.

* Corresponding author: Professor Dr K. Becker, fax +49 711 4593702, email kbecker@uni-hohenheim.de
} 
(a)

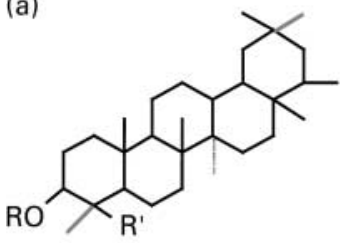

(b)

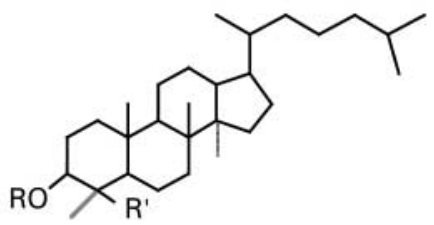

Fig. 1. Basic structures of sapogenins: a triterpenoid (a) and a steroid (b).

detected in many legumes such as soyabeans, beans, peas, lucerne, etc. and also in alliums, tea, spinach, sugar beet, quinoa, liquorice, sunflower, horse chestnut, and ginseng. Steroid saponins are found in oats, capsicum peppers, aubergine, tomato seed, alliums, asparagus, yam, fenugreek, yucca and ginseng. One example of an extensively studied group of triterpenoid saponins is produced from Quillaja saponaria, a tree native to the Andes region. The bark was peeled off and extracted with water by the indigenous peoples as a shampooing agent, and by the Shamans as an overall curing agent. Yucca schidigera is the most common commercial source of steroid saponins.

In general, very little is known about the enzymes and biochemical pathways involved in saponin biosynthesis. Triterpenoid saponins are synthesised via the isoprenoid pathway by cyclisation of 2,3-oxidosqualene to give primarily oleanane ( $\beta$ amyrin) or dammarane triterpenoid skeletons. The genetic machinery required for the elaboration of this important family of plant secondary metabolites is as yet largely uncharacterised, despite the considerable commercial interest in this important group of natural products. This is likely to be due in part to the complexity of the molecules and the lack of commercially available pathway intermediates for biochemical studies. A recent review describes the advances made in the area of 2,3-oxidosqualene cyclisation, the genes that encode enzymes giving rise to the diverse array of plant triterpenoid skeletons, and the characterisation of saponin glucosyltransferases (Haralampidis et al. 2002). A number of factors, such as physiological age, environmental and agronomic factors, have been shown to affect the saponin content of plants (for a review, see Yoshiki et al. 1998). Reports reviewed here indicate that saponins increase on sprouting in some plants such as soyabeans, lucerne, mung beans, and peas but decrease in others such as moth bean, and that light availability during germination has a profound stimulating effect on the saponin content. Generally, immature plants of a species have been found to have higher saponin contents than more mature plants of the same species.

\section{Role in plants}

The physiological role of saponins in plants is not yet fully understood. While there is a number of publications describing their identification in plants, and their multiple effects in animal cells and on fungi and bacteria, only a few have addressed their function in plant cells. Many saponins are known to be antimicrobial, to inhibit mould,

and to protect plants from insect attack. Saponins may be considered a part of plants' defence systems, and as such have been included in a large group of protective molecules found in plants named 'phytoanticipins' or 'phytoprotectants' (Morrissey \& Osbourn, 1999). The first term describes those saponins, such as A and B avenacosides in oat, that are activated by the plant's enzymes in response to tissue damage or pathogen attack (Gus-Mayer et al. 1994). The second describes those saponins that have a general anti-microbial or anti-insect activity. A glycosylated triterpenoid saponin from peas (Pisum sativum) was purified and characterised as a specific inhibitor of diguanylate cyclase, a key regulatory enzyme in the synthesis of cellulose (Ohana et al. 1998). It has also been suggested that saponins could be a source of monosaccharides (see Barr et al. 1998).

\section{Isolation and characterisation of saponins}

The unique chemical nature of saponins demands tedious and sophisticated techniques for their isolation, structure elucidation and analysis. The task of isolating saponins from plant material is complicated also by the occurrence of many closely related substances in plant tissues, and by the fact that most of the saponins lack a chromophore. Thus, for many years, the complete characterisation of saponins from even well-known saponin-containing plants was not achieved. However, recently renewed interest in medicinal plants and foods alongside the dramatic evolution of analytical tools has resulted in a burst of publications presenting numerous novel saponins. The modern methods available for the separation and analysis of saponins have been well reviewed by Marston et al. (2000), Muir et al. (2000) and Schopke (2000). These methods will be only briefly outlined in the present review.

There are several strategies available for the isolation of saponins. As a general rule, they begin with the extraction of the plant material with aqueous methanol or ethanol. Further processing of the extract is carried out after evaporation under reduced pressure, dissolution in a small amount of water and phase separation into n-butanol. It is currently recognised that this step is sometimes undesirable, since only those saponins with short oligosaccharide side chains will eventually be extracted into the butanolic phase. A further purification is then carried out, which involves liquid chromatography over a silica gel column, or a gradient elution from a polymeric support or liquidliquid partition chromatography, or, as most commonly employed, HPLC separation. In most cases, certain of the above steps have to be repeated with a change of support or eluent to achieve high purity.

Once the saponin has been purified, it may be subjected to analytical methods including MS, proton and carbon NMR, and infrared spectroscopy. Other classical methods are used to ascertain the presence of saponins in a crude plant extract, and to elucidate their composition throughout purification steps. TLC and staining with dehydrating reagents containing aromatic aldehydes (such as anisyl aldehyde in sulfuric acid) are commonly used. The pure saponin may also be hydrolysed to verify the nature of its glycosidic moieties. 


\section{Biological effects in animals}

\section{Effects on cell membranes}

Permeabilisation and effects on other membrane properties. A large number of the biological effects of saponins have been ascribed to their action on membranes. In fact, their specific ability to form pores in membranes has contributed to their common use in physiological research (El Izzi et al. 1992; Authi et al. 1988; Choi et al. 2001; Menin et al. 2001; Plock et al. 2001). Saponins have long been known to have a lytic action on erythrocyte membranes and this property has been used for their detection. The haemolytic action of saponins is believed to be the result of the affinity of the aglycone moiety for membrane sterols, particularly cholesterol (Glauert et al. 1962), with which they form insoluble complexes (Bangham \& Horne, 1962). The amount of glycosides required for permeabilisation is much lower for cholesterol-rich lipid layers than cholesterol-free membranes (Gögelein \& Hüby, 1984). Isolated cell membranes from human erythrocytes when treated with saponin developed pores of $40-50 \AA$ diameter as against the $80 \AA$ pores produced in artificial membranes (Seeman et al. 1973). Compared with the reversible perforations caused by substances such as vitamin A, the membrane pores or defects produced by saponins were long-lasting and such membranes were then permanently permeable to large molecules like ferritin (Seeman, 1974). The lesions that are caused by saponins are thought to be a micelle-like aggregation of saponins and cholesterol in the plane of the membrane, possibly with saponin molecules arranged in a ring with their hydrophobic moieties combined with cholesterol around the outer perimeter (Bangham \& Horne, 1962; Seeman, 1974). Other reports depict the interactions between saponins and biological membranes to be more complex. Brain et al. (1990) showed that insertion of the aglycone into the lipid bilayer is independent of the presence of cholesterol. Saponins could induce a permeability change on liposomal membrane without cholesterol when they are glycosylated at both $\mathrm{C}_{3}$ and $\mathrm{C}_{28}$ (bidesmosidic) of the oleanolic aglycone (Hu et al. 1996). Abe et al. (1978a) observed no close and direct relationship between the haemolytic activity of saikosaponin (from Bupleurum falcatum ) and membrane-permeabilising activity, nor was it correlated with either their surface or interfacial tension-lowering properties (Pillion et al. 1996; Steurer et al. 1999). The efficacy as absorption-enhancing agents across nasal mucosa in rats was greatest in those Quillaja saponins with the lowest surfactant strength and haemolytic titres (Pillion et al. 1996).

Cholesterol enrichment was shown to have an inhibitory effect on many membrane ATPases, as it may directly interact with the boundary lipids of ATPase and alter the intermolecular hydrogen bonds of the protein. Ginsenosides (from Panax quinquefolius and P. japonicus) share the steroid backbone and amphipathic nature with cholesterol. The desacyl-jego-saponin (from Styrax japonica) and gensenoside-Rd, which had little or no effect on membrane permeability, were capable of stimulating $\mathrm{Na}^{+}-\mathrm{Ca}^{+}$ exchange activity in canine cardiac sarcolemmal vesicles (Yamasaki et al. 1987; Choi et al. 2001). However, not all ginsenosides alter the $\mathrm{Na}^{+}-\mathrm{K}^{+}$ATPase and $\mathrm{Ca}^{2+}$ $\mathrm{Mg}^{2+}$ ATPase activity in neurones in the same manner (Choi et al. 2001). It is possible that some ginsenosides interact with membrane cholesterol and displace it from the immediate environment of ATPases. Since removal of cholesterol will lead to an increase in membrane fluidity, conformational changes that ATPases undergo during their transport cycle may be facilitated. Membrane fluidity controls the enzyme activity of biological membranes and has an important role in ion transport (Ma \& Xiao, 1998) and the ability of saponins to affect this parameter may explain their effects on cellular function. The inotropic action of saponins, supposed to be caused by their effect on membrane $\mathrm{Ca}^{2+}$ channels, also did not have any simple correlation with membrane permeability effect (Enomoto et al. 1986). Saponins such as ophiopogonins and ginsenocides haemagglutinated human, rabbit, and sheep erythrocytes but were not haemolytic (Takechi \& Tanaka, 1995a). They were thus able to bind to the membrane lipids of erythrocytes and form bridges between the cells. Other studies (Gögelein \& Hüby, 1984) explained the increase in electrical conductance caused by saponins in planar lipid bi-layers to be due to fluctuating membrane channels. Soyasaponins I and III, and dehydrosoyasaponin I (isolated from Desmodium adscendens ) have been shown to be able to open large $\mathrm{Ca}$-dependent $\mathrm{K}$ (maxi-K) conductance channels causing membrane hyperpolarization, suppression of electrical activity and relaxation of smooth muscle (McManus et al. 1993). On the other hand there are also reports of the ability of saponins to block membrane ion channels on neurons (Kai et al. 1998) and human neutrophils (Bei et al. 1998). The interactions are therefore complex and may involve different mechanisms.

The side chains present on the aglycone such as sugar chains (Segal et al. 1974; Santos et al. 1997), acyl recidues (Matsuda et al. 1997) or the epoxy-framework system (Abe et al. 1978b) are also supposed to contribute to the effects on membranes. These effects however were not uniform; for example some saponins with acyl residue (lablaboside D) did not show haemolytic activity (Oda et al. 2000), while in another work, only acylated triterpenoid saponins in low concentrations were able to alter membrane activity (Melzig et al. 2001). In the latter case, it was suggested that only acetylated saponins might integrate transiently into membranes, thus inducing pore-like structures. It has been suggested that the haemolytic activity of saponins increases with increasing numbers of polar groups in the aglycone moiety (Namba et al. 1973). Carbohydrate chain length was shown to influence the manifestation of physiological activity of oligosides (Kuznetzova et al. 1982). Steroid and triterpenoid saponins with a single sugar chain (monodesmosides) were found to have strong haemolytic activity, whereas those with two sugar chains (bidesmosides) showed less activity (Fukuda et al. 1985; Woldemichael \& Wink, 2001). Even though monodesmoside saponins are generally considered to be more active than bidesmosides, there are exceptions. For example, among fifteen synthetic methyl ursolate glycosides, diand triglycosides showed much higher haemolytic activity than monoglycosides (Takechi \& Tanaka, 1995b). It was also observed that an increase in sugar moieties enhanced 
the effects of saponins on sarcolemmal membrane $\mathrm{Ca}^{2+}$ permeability (Yamasaki et al. 1987). The permeabilising activity of the native avenacin A-1 was completely abolished after one, two, or all three sugar residues were hydrolysed to yield mono-deglucosyl, bis-deglucosyl, and aglycone derivatives respectively (Armah et al. 1999). De-acylated Quillaja saponins 1 and 2, which differ only in the absence of one glucose residue, differed significantly in their ability to stimulate absorption of insulin despite having similar surfactant strength and haemolytic potency (Pillion et al. 1996). The stereochemistry of the terminal sugar on the saccharide chain also appears to be important in conferring activity on the saponin molecule because of its ability to affect the overall shape of the molecule (Gee et al. 1998). The relationship between increased saccharide branching and increased permeabilising activity and the haemolytic property of saponins was not a direct one (Price et al. 1994) due to the large number of factors involved. Generally both the aglycone and glycan parts seem to play a role in the haemolytic activity of saponins (Apers et al. 2000). The neutral and acidic triterpenoids, and the acyl glycosides are very weakly active, whereas the ester saponins (for example, maesasaponins) are strongly haemolytic.

The interaction between saponins and membrane lipids thus seems to be complicated, with the composition of the target membrane, the type of side chain, and the nature of the aglycone to which these are attached all appearing to be necessary to produce a permeabilising effect (Gee et al. 1998; Attele et al. 1999). Cellular membranes may exist under conditions of curvature stress, being close to the hexagonal phase transition. Consequently, the physicochemical properties of these membranes are sensitive to changes in membrane components and lipophilic agents, which may modulate curvature stress. Membrane proteins are thought to be localised selectively in cholesterol-rich domains (acetylcholine receptor) or in cholesterol-poor domains (the sarcoplasmic $\mathrm{Ca}^{2+}$ ATPase). Therefore, the biophysical properties of the different domains, rather than the bulk lipid, may selectively influence transmembrane protein function and mimic specificity at the effector level. Saponins may interact with the polar heads of membrane phospholipids and the $-\mathrm{OH}$ group of cholesterol through $\mathrm{OH}$ groups at $\mathrm{C}_{3}$ or $\mathrm{C}_{28}$, which will result in their later ability to form micelle-like aggregates. Moreover, their hydrophobic aglycone backbone could intercalate into the hydrophobic interior of the bilayer. Both of these effects may contribute to the alteration of the lipid environment around membrane proteins. It has become increasingly evident that the lipid environment of membrane proteins, including ion channels, transporters, and receptors, plays an important role in their function. The changed-function proteins or glycoproteins in the plasma membranes have been suggested to be the cause of secondary biochemical responses induced by saponins (Abe et al. 1978b; Rao \& Sung, 1995).

The precise details of the interactions between saponins and membranes need more elucidation so that the molecular mechanisms involved could be better understood. It seems likely that different mechanisms such as the formation of the saponin-cholesterol complex, alterations in the organisation of sarcolemmal membrane phospholipids, and the formation of phospholipid breakdown products such as phosphatidic acid (Yamasaki et al. 1987) in addition to saponin structure and three-dimentional orientation are all involved in the actions of saponins on membranes.

Effects on nutrient uptake through the intestinal membrane. Johnson et al. (1986) found that some saponins increase the permeability of intestinal mucosal cells in vitro, inhibit active mucosal transport and facilitate uptake of substances that are normally not absorbed. Saponins (from Gypsophila, Quillaja, clover, guar and lucerne) also lower transmural potential difference (TPD, the electrochemical gradient that acts as a driving force for active nutrient transport across the brush border membrane of the intestine) across the small intestine of the rat (Gee et al. 1989). Here the stereo-structure of the saccharide chain appeared to be an important feature in conferring this ability. Soyasaponins with a non-acidic triterpenoid moiety coupled to a straight-chain tri-saccharide caused only a small drop in TPD in Wistar rat intestines in vitro whereas saponins from Gypsophila, lucerne and guar, which contain acidic triterpenes coupled to branched tetrasaccharide moieties caused significant changes in TPD. Among lucerne saponins (glycosides of medicagenic acid), bidesmosides containing four sugar moieties reduced rat-intestine TPD in vitro in a similar fashion to the monodesmoside and to medicagenic acid itself (one exception was 3Glc, 28Glc-medicagenic acid which had no effect on TPD) (Oleszek et al. 1994). The tridesmoside of zahnic acid, which is only weakly haemolytic and which neither inhibits fungal growth nor forms insoluble complexes with cholesterol, was the most active compound, giving further evidence of the complexity of the interactions between saponins and membranes.

An increase in the apparent permeability of the brush border observed at sublethal levels of saponins may have important implications for the uptake of macromolecules, such as allergens, whose passage through the epithelium is normally somewhat restricted (Gee et al. 1996). The presence of Gypsophila saponins enhanced the uptake of $\beta$ lactoglobulin, a milk allergen in the jejunal loops' tips of brown Norway rats (Gee et al. 1997). Histological investigation of the mucosal epithelium exposed to saponin revealed damage, especially of the villi. Rats fed the unwashed bitter quinoa diets (containing saponins that caused rapid depolarisation of the small-intestinal mucosa, even at concentrations of less than $50 \mu \mathrm{g} / \mathrm{ml}$ ) demonstrated growth impairment and decreased food conversion efficiency (Gee et al. 1993). Avenacosides that were haemolytic in the crude extract significantly increased the passage of ovalbumin in rat intestine in vitro at a concentration of $1 \mathrm{mg} / \mathrm{ml}$ but did not affect the active transport of glucose (Onning et al. 1996). However, when given in vivo in the same experiment the saponins did not affect the transport of bovine serum albumin across the intestine wall. Quillaja saponins were able to increase uptake of human $\Gamma$ globulin into the body, when fed to tilapia or administered by anal incubation (Jenkins et al. 1991; Anderson, 1992). Rat intestines have been shown to 
offset the damage to small-intestinal mucosal cells caused by dietary saponins (up to $1.5 \%$ ) by continuous proliferation (Gee \& Johnson, 1988).

Some reports describe obstruction of the absorption of micronutrients by dietary saponins. Gypsophila saponins in the diet depressed mean liver $\mathrm{Fe}$ concentrations and total liver $\mathrm{Fe}$ by impairing $\mathrm{Fe}$ absorption (Southon et al. 1988). Probably the saponin formed complexes with dietary $\mathrm{Fe}$ rendering it unavailable for absorption. Lucerne saponins were shown to increase excretion of $\mathrm{Fe}$ and $\mathrm{Mg}$ when present in rat diets, and reduce plasma $\mathrm{Ca}$ and $\mathrm{Zn}$ in pigs (for references, see Southon et al. 1988). These saponins could complex with $\mathrm{Fe}$ and $\mathrm{Zn}$ in vitro and this complex formation might have hindered their absorption. Triterpenoid saponins from Gypsophila and Quillaja included in the diet appeared to interfere with the absorption of vitamins $\mathrm{A}$ and $\mathrm{E}$ in chicks (Jenkins \& Atwal, 1994). Feeding a steroid saponin (sarsasaponin) at the same level had no effect on any of these parameters.

The mechanism of action of saponins on the intestinal membranes in vivo is not yet clearly understood. Ingested saponins are exposed to many potential ligands in the intestine such as bile salts, dietary cholesterol and membrane sterols of the mucosal cells, and nutrients or antinutrients in food, all of which may reduce or enhance their effectiveness. It also remains to be confirmed whether traces of the compound itself enter the body through the permeabilized membranes, even though all the evidence until now points to their non-absorption (Yoshikoshi et al. 1995). Absorption of saponin metabolites produced in the intestine by micro-organisms into the body of ruminants (Flaoyen et al. 2001; Meagher et al. 2001) and human subjects (Wakabayashi et al. 1997; Lee et al. 2000c) has, however, been demonstrated.

\section{Effects on animal growth and feed intake}

Animal nutritionists have generally considered saponins to be deleterious compounds. In ruminants and other domestic animals the dietary saponins have significant effects on all phases of metabolism, from the ingestion of feed to the excretion of wastes (Cheeke, 1996). Lucerne and soya beans are the main examples of saponin-rich plants that serve extensively in human, ruminant and poultry diets. Recently, a number of studies have reported both beneficial and adverse effects of these compounds in a variety of animals (for a review, see Sen et al. 1998).

Effects in ruminants. $Y$. schidigera plant extract (the plant is common in south and central America where it is used as animal feed, and like many other saponin-rich plants, as a herbal medicine) has been found to improve growth, feed efficiency and health in ruminants (Mader \& Brumm, 1987). Quillaja saponins increased the efficiency of in vitro rumen-microbial protein synthesis and decreased degradability of feed protein (Makkar \& Becker, 1996). Partially hydrolysed lucerne saponins administered intra-ruminally resulted in a significant reduction in the total protozoa count in the rumen of sheep (Lu \& Jorgensen, 1987) which may be the reason for the decrease in feed protein degradability. Saponins are considered to have detrimental effects on protozoa through their binding with sterols present on the protozoal surface. Sterols are absent on bacterial membranes. Yucca extract can also bind $\mathrm{NH}_{4}$ when ruminal $\mathrm{NH}_{4}$ concentrations are high, and release it again when ruminal $\mathrm{NH}_{4}$ is low, providing a continuous and adequate supply of $\mathrm{NH}_{4}$ for microbial protein synthesis (Hussain \& Cheeke, 1995). A positive effect of Yucca saponins in ruminant nutrition was attributed to the enhancement of the entrapment of $\mathrm{NH}_{4}-\mathrm{N}$ from urea-supplemented straw (Makkar et al. 1999). This increases the availability of nutrients to rumen bacteria and reduces environmental damage by decreasing losses of $\mathrm{NH}_{4}$ to the air. Supplementation of feed with leaves of Sesbania sesban, known for its high saponin content, has been found to have the potential to improve protein flow from the rumen by suppressing protozoal action there (Newbold et al. 1997) but rumen bacteria were observed to be capable of metabolising the antiprotozoal factor. Saponins may also be degraded by the saliva of sheep fed saponin-rich foods for a long time (Odenyo et al. 1997; Teferedegne, 2000). GC-MS analysis of tissue samples (bile, urine, rumen, duodenum, jejunum, colon and rectum, and faeces) from sheep fed Narthecium ossifragum (containing mainly sarsasapogenin and smilagenin) for $6 \mathrm{~d}$, followed by $20 \mathrm{mg}[20,23,23-\mathrm{H}-2(3)]$ sarsasapogenin/d on the seventh day revealed only negligible levels of ${ }^{2} \mathrm{H}$-labelled sarsasapogenins in these organs (Flaoyen et al. 2001). Ingested saponins were quickly hydrolysed in the rumen to free sapogenins and, in part, epimerized at $\mathrm{C}_{3}$ into episapogenins. The absorption of free sapogenins appeared to occur in the jejunum. The concentration of sapogenins in faeces reached a plateau $108 \mathrm{~h}$ after dosing started.

The positive effects of saponins were more pronounced when they were directly administered into the rumen rather than added to the feed (Odenyo et al. 1997). Killeen et al. (1998) proposed that a surfactant or flocculent action of saponins on the feed constituents that alters the rate of digestion would account for the substrate-dependent nature of the effect of $Y$. schidigera on rumen DM and $\mathrm{N}$ digestibility. This substrate-dependency might also be due to negative effects of saponins on specific bacterial populations (Hussain \& Cheeke, 1995). Wang et al. $(2000 a, b)$ observed that supplementation with Yucca extracts might be beneficial to ruminants fed a high-grain diet. Yucca saponins were found to have a direct negative effect on cellulolytic bacteria while being harmless to amylolytic bacteria, suggesting the possibility of using saponins for 'designing' the rumen population. The mechanism of action against bacteriae remains unclear. Other reports point to the fact that some of the effects of dietary saponins in lambs are sex-dependent. Bosler et al. (1997) found that both male and female lambs fed up to $40 \mathrm{mg}$ Quillaja saponin/kg mixed with a basal diet had significantly higher average daily weight gains than controls but that the difference in weight gain was lower in the females. The dietary saponins reduced the fat deposits around the kidney in females while increasing it in males.

Dietary saponins were often suspected of having a role in causing ruminant bloat (Cheeke, 1996; Sen et al. 1998), but clear experimental proof for this is lacking in the literature. The absence of any positive effect in 
experiments where Yucca saponins were fed to ruminants (for example, $\mathrm{Wu}$ et al. 1994) might have been because animals with adapted rumen microbial population were used.

Effects in fish. Saponins have been reported to be highly toxic to fish because of their damaging effect on the respiratory epithelia (Roy et al. 1990). They are also considered to be the active components of many traditionally used fish poisons, like mahua oil cake (see Francis et al. 2001a). Fish have also been shown to exhibit stress reactions to the presence of saponins in water. Roy \& Munshi (1989) reported that the $\mathrm{O}_{2}$ uptake of perch (Anabas testudineus) increased with a concomitant increase in the erythrocyte, haemoglobin and packed cell volume levels, after the fish had been in water containing $5 \mathrm{mg}$ Quillaja saponin/l for $24 \mathrm{~h}$. Penaeus japonicus that had been previously exposed to concentrations of $20 \mathrm{mg}$ saponin/1 for $24 \mathrm{~h}$ increased both respiration rate and metabolism (measured as increase in $\mathrm{O}_{2}$ uptake and $\mathrm{NH}_{4}$ excretion) during a $6 \mathrm{~h}$ detoxification process (Chen \& Chen, 1997). Bureau et al. (1998) observed that Quillaja saponins damaged the intestinal mucosa in rainbow trout and Chinook salmon at dietary levels above $1.5 \mathrm{~g} / \mathrm{kg}$. The condition of the intestines of these fish was similar to that of fish fed a raw soyabean-meal diet indicating the role of saponins in causing the damage. Krogdahl et al. (1995), however, did not find any negative effects when saponins were included in the diet of Atlantic salmon at levels similar to those likely to be found in a soyabean meal $(300-400 \mathrm{~g} / \mathrm{kg})$-based diet. In the same study, an alcohol extract of soyabean meal caused growth retardation, altered intestinal morphology, and depressed mucosal enzyme activity in the lower intestine. Dietary levels of triterpenoid Quillaja saponins of $150 \mathrm{mg} / \mathrm{kg}$ showed potential for promoting growth and nutrient utilisation in common carp and tilapia (Francis et al. 2001b, 2002a). Growth in common carp was significantly higher than control only when there was a continuous dietary supply of the saponins (Francis et al. 2002b). The growth-promoting effect was not pronounced in common carp fed steroid $Y$. schidigera saponins ( $\mathrm{G}$ Francis, unpublished results). The effects of dietary saponins in fish such as higher growth, reduced $\mathrm{O}_{2}$ consumption and metabolic rate that we observed (Francis et al. 2001b; 2002a,b) point to a possible systemic effect. The mechanisms whereby Quillaja saponins increased the growth and food conversion efficiency in fish remain to be ascertained.

Effects in other single-stomached animals. Legume grains form the staple food in a large part of the world, and serve also as the largest source for plant protein. Surprisingly there are only scarce reports on the effects of soyasaponins (common among legumes other than soyabean as well) on mammals, birds and cold-blooded organisms but for a few reports during the late 60 s to the early 70 s of the 20th century. Soyabean saponins did not impair growth of chicks when added at five times the concentration in a normal soyabean-supplemented diet (Ishaaya et al. 1969). In the same work they observed no effect on the growth response of rats and mice or on the amount of ingested food. Y. schidigera extract has also been found to improve growth, feed efficiency and health in poultry and pigs by mechanisms that are not as yet understood (Johnston et al. 1981, 1982; Mader \& Brumm, 1987; Anthony et al. 1994). Male Wistar rats, given 10 and $100 \mathrm{mg}$ fenugreek extract $/ 300 \mathrm{~g}$ body weight mixed with their food had significantly higher feed intake and appetite (Petit et al. 1993). The circadian rhythm of feeding behaviour was modified so that the rats fed the fenugreek extract ate continuously during $24 \mathrm{~h}$ rather than just at night (Petit et al. 1995).

There are also numerous reports of negative effects of dietary saponins. Dietary saponins depressed growth, feed consumption in gerbils and egg production in poultry (Sim et al. 1984; Terapunduwat \& Tasaki, 1986; Potter et al. 1993; Jenkins \& Atwal, 1994). These negative effects have been ascribed to several properties of saponins such as reduced feed intake caused by the astringent and irritating taste of saponins (see Oleszek et al. 1994), reduction in intestinal motility (Klita et al. 1996), reduction in protein digestibility (Shimoyamada et al. 1998) and damage to the intestinal membrane and inhibition of nutrient transport described earlier in the present review. Production of active metabolites (see Wakabayashi et al. 1998) by hydrolysis of saponins by intestinal bacteria (Bae et al. 2000) also needs to be considered. More investigations are required into the fate of ingested saponins in the digestive tract of ruminants and single-stomached animals.

\section{Effects on protein digestion}

Saponins reduce protein digestibility probably by the formation of sparingly digestible saponin-protein complexes (Potter et al. 1993). Endogenous saponins affected the chymotrypsic hydrolysis of soyabean protein, particularly glycinin (Shimoyamada et al. 1998). The heat stability of bovine serum albumin was increased by the addition of soyasaponin due to electrostatic and hydrophobic interactions. The digestibility of the bovine serum albuminsoyasaponin complex was much lower than that of free bovine serum albumin indicating that complexing with saponin had an obstructing effect. Soyasaponin seemed to slightly activate $\alpha$-chymotrypsin, but the effect was not great (Ikedo et al. 1996). It has also been shown that casein and Quillaja saponin form complexes of high molecular weight at elevated temperatures $\left(78^{\circ} \mathrm{C}\right)$. Starfish saponin accelerated the thermal aggregation of actomyosin from walleye pollack muscle (Ishisaki et al. 1997). This enhancing effect increased concomitantly with increase in starfish saponin:actomyosin. Quillaja saponin was also reported to accelerate the thermal aggregation of actomyosin (Ishisaki et al. 1997). The same research group showed that tea saponins had the ability to suppress the heat denaturation of salt-soluble proteins from fish, while Quillaja saponin accelerated the reaction indicating a lack of uniformity in the way saponins act with regard to these effects.

A large number of foods and feed materials contain both saponins and proteins. The nature of the interactions between them would influence the nutritive value of a diet, and hence these interactions need to be studied to elucidate possible structure-activity relationships. 


\section{Hypoglycaemic activity}

Saponins isolated from plants such as fenugreek (Petit et al. 1993), Phellodendron cortex and Aralia cortex (Kim et al. 1998c), Pueraria thunbergiana (Lee et al. 2000a), and Calendula officinalis (Yoshikawa et al. 2001) have been shown to have hypoglycaemic effects. Petit et al. (1993) found chronically higher plasma insulin levels, probably caused by stimulation of the $\beta$-cells in male Wistar rats given 10 and $100 \mathrm{mg}$ fenugreek extract/300 g body weight mixed with food while Matsuda et al. (1999b) did not find insulin-like or insulin-releasing activity in rats given oleanolic acid glycosides orally. The hypoglycaemic action here was due to suppression of the transfer of glucose from the stomach to the small intestine and the inhibition of glucose transport across the brush border of the small intestine. The saponin momordin Ic was also found to significantly and dose-dependently inhibit gastric emptying (Matsuda et al. 1999a). The inhibitory activity here was dependent on the level of serum glucose and mediated at least in part by the capsaicin-sensitive sensory nerves and the central nervous system. Yoshikawa et al. (2001) showed that the oleanolic acid 3-monodesmosides with hypoglycaemic activity also inhibited gastric emptying showing a correlation between the two effects, while other saponins showing no hypoglycaemic activity in the mixture also did not affect gastric emptying.

\section{Effects on cholesterol metabolism}

A number of studies have shown that saponins from different sources lower serum cholesterol levels in a variety of animals including human subjects (Southon et al. 1988; Harwood et al. 1993; Potter et al. 1993; Matsuura, 2001; also, for a review, see Al-Habori \& Raman, 1998). Large mixed micelles formed by the interaction of saponins with bile acids account for their increased excretion when saponin-rich foods such as soyabean, lucerne and chickpea are consumed (Oakenfull, 1986; Oakenfull \& Sidhu, 1990). The resulting accelerated metabolism of cholesterol in the liver causes its serum levels to go down. The ethanol extract of de-fatted fenugreek seeds inhibited taurocholate and deoxycholate absorption in vitro, in a dose-dependent manner in everted intestinal sacs (Stark \& Madar, 1993). Decreased intestinal cholesterol absorption induced by some saponins, however, was seen to be without interference with the entero-hepatic bile acid recirculation (Harwood et al. 1993). Saponins also reduced the more harmful LDL-cholesterol selectively in the serum of rats, gerbils and human subjects (Potter et al. 1993; Harris et al. 1997; Matsuura, 2001). Morehouse et al. (1999) found that the mechanism of action of saponins was luminal but did not involve stoichiometric complexation with cholesterol. They also found that the synthetic saponins tiqueside and pamaqueside were much more potent than naturally occurring saponins such as those from lucerne in preventing hypercholesterolaemia and that the in vivo potency of pamaquecide was 10-fold that of tiqueside even though it differs from tiqueside only by an additional keto group. Other suggested mechanisms of action of saponins include delaying the intestinal absorption of dietary fat by inhibiting pancreatic lipase activity (Han et al. 2000).

Not all reports, however, agree on the anticholesterolaemic activity of saponins. Soyabean and lucerne saponins were found to be not singularly responsible for the hypocholesterolaemic effect of diets containing them (Calvert \& Blight, 1981; Story et al. 1984; Sugano et al. 1990). Results from our laboratory showed that the level of muscle cholesterol in tilapia fed small amounts of Quillaja saponins (up to $300 \mathrm{mg} / \mathrm{kg}$ ) was higher than that of controls (Francis et al. 2001b), while the serum levels were not different from control (G Francis, unpublished results). It has also been noted that a saponin-induced reduction of serum cholesterol occurred only when a hypercholesterolaemic diet had been fed (Jenkins \& Atwal, 1994).

There is also evidence of increased cholesterol synthesis to compensate for saponin-induced excretion (Jenkins \& Atwal, 1994). Dietary sarsasaponin failed to lower the cholesterol content of egg yolk or the serum of laying hens even though it increased the excretion of cholesterol and decreased the transfer of dietary cholesterol to the eggs (Sim et al. 1984).

It can be concluded that several dietary saponins do have a hypocholesterolaemic action. Since cholesterol binding takes place in the intestinal lumen, factors such as quantity of saponins and cholesterol, and the presence of other ligands of both these compounds may play a role and these may have caused the observed discrepancies among the various results. Knowledge of the nature of the interaction between the particular saponin and cholesterol, and the nature of the cholesterol moieties and other ligands in the diet are essential to arrive at an effective dietary dose of that particular saponin that could have a significant hypocholesterolaemic effect.

\section{Effects on animal reproduction}

The negative effects of saponins on animal reproduction have long been known and have been ascribed to their abortifacient, antizygotic and anti-implantation properties (Tewary et al. 1973; Stolzenberg \& Parkhurst, 1976). Saponins from broom weed (Gutierrezia sp.) and lechuguilla (Agave lecheguilla) or commercial pharmaceuticalgrade saponins caused abortion or death or both in rabbits, goats and cows when administered intravenously at concentrations above $2.3 \mathrm{mg} / \mathrm{kg}$ body weight (Dollahite et al. 1962). Saponins isolated from the crude extract of Gleditischia horrida, Costus speciosus $\mathrm{Sm}$ and Phytolacca dodecandra caused sterility in mice (Chou et al. 1971; Tewary et al. 1973; Stolzenberg \& Parkhurst, 1976). Quin \& Xu (1998) found that the butanol extract of Mussaenda pubescens was capable of terminating pregnancy in rats. Extracts of this plant are used as a contraceptive in the Fujian province of China.

Saponins were found to be extremely strong stimulators of luteinising hormone release from cultured hypophysial cells (El Izzi et al. 1989; Benie et al. 1990) but their action was neutralised in the presence of serum indicating a passive membrane-permeabilising effect (El Izzi et al. 1992) in this case. However, saponin-rich extracts from Combretodendron africanum injected into female rats 
stimulated uterine growth, lowered luteinizing hormone release, and blocked the oestrous cycle (Benie et al. 1990). The steroidal saponin $3 \beta, 16 \beta, 17 \alpha$-tri-hydroxycholest-5-en-22-one 16-0-(2-0-4-methoxybenzoyl- $\beta$-Dxylopyranosyl)-( $1 \rightarrow 3)-(2-0$-acetyl- $\alpha$-L-arabinopyranoside) (or OSW-1) isolated from Ornithogalum saundersiae injected into rats on the morning of pro-oestrous at a level of $9 \mu \mathrm{g} / \mathrm{kg}$ inhibited oestrogen production and prolonged the period of dioestrous (Tamura et al. 1997). The steroid saponin was found to directly inhibit the genes responsible for steroidogenesis, and also suppress the proliferation of follicle-stimulating hormone-modulated granulosa cells in the ovarian follicle. The mechanism of suppression of cell proliferation here might be through a similar mechanism as saponin-induced proliferation of tumour cells.

Saponins have been shown to have both positive and negative effects on the viability of human sperm cells in vitro with some ginseng saponins increasing motility as well as progression of sperm (Chen et al. 1998) while Sesbania sesban saponins were spermicidal at $1.0-1.3 \mathrm{mg} / \mathrm{ml}$ (Dorsaz et al. 1988). It is debatable how relevant these in vitro effects are for dietary saponins as there are relatively few reports in this regard.

Saponin-rich extracts of Turnera diffusa and Pfaffia paniculata improved the copulatory performance of sexually sluggish or impotent rats while being ineffective in sexually potent rats (Arletti et al. 1999), which the authors ascribed to increased central noradrenergic and dopaminergic tone, and possibly oxytocinergic transmission. We have observed inhibitory effects of dietary Quillaja saponins on egg production in Nile tilapia (Francis et al. $2001 b$ ). Saponins also reportedly affect functioning of the male reproductive system. The gonado-somatic index of 6-month-old male tilapia fed a diet containing Quillaja saponins during the initial part of the life-cycle was significantly higher than that of the control, whereas male tilapia receiving a continuous supply of dietary saponins tended to have lower gonado-somatic index (G Francis, unpublished results). The mechanism of action in these instances remains to be clarified.

The in vivo effects of saponins on the reproductive functioning seem to indicate more than a simple permeabilising effect on secretary cell membranes and could possibly be linked to interactions between saponins and steroid receptors given the similarities between the basic chemical structures of saponins and steroid hormones. Ginseng saponins were found to compete strongly with oestradiol and R5020 (a synthetic progestin) for oestrogen- and progesterone-binding sites in the human myometrial cytosol (Punnonen \& Lukola, 1980). C. africanum extract was shown to compete with oestradiol and with progesterone on uterine receptors (Benie et al. 1990). The spirostanol-steroid saponin, digitonin, stimulates binding of progesterone to bovine luteal membrane and this action is mediated by its ability to specifically complex with membrane sterols rather than by a non-specific detergent effect (Menzies et al. 1999). The saponin receptor complexes may then translocate into the nucleus and affect transcription patterns. Ginsenoside $\operatorname{Rg} 3$ (20(s) protopanaxadiol type) exhibited a dose-dependent inhibitory activity on the expression of marker genes coding for androgen receptors and $5 \alpha$ reductases that converts testosterone into the more potent dihydrotestosterone, which in turn binds to androgen receptors for eliciting its actions (Liu et al. 2000).

\section{Effects on the immune system}

Saponin-based adjuvants have the unique ability to stimulate the cell-mediated immune system, as well as to enhance antibody production, and have the advantage that only a low dose is needed for adjuvant activity (Oda et al. 2000). There have been quite a few reviews on the immunostimulatory activity of saponins (Kensil, 1996; Barr et al. 1998; Sjolander et al. 1998). Our attempt here would be to look more closely at the mechanisms involved, including from a nutritional point of view, and relationships between structures and activities. Research thus far has concentrated on Quillaja saponins and derivatives such as immune-stimulating complex vaccines (immunestimulating complexes formed by the combination of cholesterol, saponin, phospholipid and amphiphatic proteins). Quillaja and other saponins either as crude mixtures or as purified compounds have been reported to increase immune-cell proliferation in vitro (Chavali et al. 1987; Plohmann et al. 1997; Lacaille-Dubois et al. 1999). Purified Quillaja saponins boosted antibody production without producing any reaginic antibodies (So et al. 1997). Immune-stimulating complexes formulated with Quillaja saponin preparations induced specific cytotoxic T-lymphocyte responses (Coulter et al. 1998) and have been reported to induce antibody responses and/or protective immunity in guinea-pig, turkey, cat, rabbit, dog, seal, sheep, pig, cow, horse and monkeys (Mowat et al. 1999). The adjuvant action of saponins was, however, not so pronounced in some of the non-mammalian species tested. For example, saponin adjuvant when injected intraperitoneally had little effect on the humoral immune response in rainbow trout (Cossarni-Dunier, 1985). Neither did the use of Quillaja saponins produce any improvement in the immune response to Yersinia ruckeri, the causative agent of enteric redmouth disease in rainbow trout, despite some enhancement of the in vivo bacterial clearance (Grayson et al. 1987).

The mechanisms of immune-stimulating action of saponins have not been clearly understood, but many explanations have been put forward. Saponins reportedly induced production of cytokines such as interleukins and interferons that might mediate their immunostimulant effects (Jie et al. 1984; Kensil, 1996). It is likely that they interact with antigen-presenting cells to induce many of these responses (Barr et al. 1998). The incorporation of the saponins into cell or endosomal membranes might expose the incorporated antigen to cytosolic proteases.

The effects of saponins at the intestinal level may also need attention, given its presence in some common dietary ingredients. Also several important systemic infections gain access to the body via the intestinal route. Infections of the intestine, along with the respiratory tract, and urogenital tract are the most common cause of mortality and morbidity in man (World Health Organization, 1996). It 
has long been considered that a single dose of orally administered sub-unit vaccine would be the most useful means of protecting against these disorders (Bloom, 1989; McGhee et al. 1992). Oral vaccines are easy and economical to administer and avoid the hazards of routes involving needles. More importantly, induction of effective immunity at a mucosal site can only be achieved by immunisation via a mucosal route. There is evidence that saponins may increase the immune response by increasing the uptake of antigens from the gut and other membranes. The example of immune-stimulating complexes was mentioned earlier. Oral administration of Panax ginseng C. A. Meyer saponins (Jie et al. 1984), Quillaja saponins (Maharaj et al. 1986), and the butanol extract of Lonicera japonica (Lee et al. 1998), and de-acylated saponin-1 administered on the nasal mucosa (Recchia et al. 1995), all stimulated the immune responses in vivo. Purified Quillaja saponin-21 was able to act as a mucosal adjuvant in DNA vaccination against HIV-1 (Sasaki et al. 1998). The saponins may also protect the antigens from digestive degradation by forming complexes with them. The permeation potential of saponins may become important when a systemic response is induced at the intestine. Deacylated saponin-1, for example, was an efficacious intestinal permeation-enhancing agent with low adverse effect on the epithelial viability and barrier function (Chao et al. 1998). Human defence strategies, although far from perfect, have evolved since inception. As such, innate reactions that appear to contribute to disease initiation and propagation are likely to have an underlying initial advantageous response for the individual. An alteration in intestinal permeation in response to insult or antigenic challenge is no exception to this rationale. Normally, luminal antigens are sampled in a more controlled fashion by $\mathrm{M}$ cells and other antigen-presenting cells in the bowel. Antigens then are presented to undifferentiated immunocompetent cells that mature and hone back to mucosal surfaces, including the gut. This is an essential function because it provides a sensitised line of defence should an insult from a like or similar antigen be mounted (DeMeo et al. 2002).

The adjuvant activity of saponins was thought to be related to branched sugar chains or aldehyde groups (Bomford et al. 1992) or to an acyl residue bearing the aglycone (Kensil, 1996). Later soyasaponins and lablabosides were found to show strong adjuvant activity despite lacking acyl residues and possessing only unbranched sugar chains (Oda et al. 2000). Also most of the escins that have acyl residues and branched sugar chains did not show adjuvant activity. Adjuvant activity and toxicity, but not the cholesterol-binding capacity of QH-B, a Quillaja fraction, declined on peroxidate oxidation due to alterations in the structure of the sugars, galactose and xylose. Modification of the apiose moiety may influence adjuvant activity but not toxicity in vivo (Ronnberg et al. 1997). Oda et al. (2000) concluded that the overall juxtaposition of hydrophilic and hydrophobic functional groups, rather than the structures of individual groups, is the essential element that confers adjuvanticity. Soyasaponins, lablabosides and purified Quillaja saponin-21, which possess adjuvant action have only two to four $\mathrm{O}$ atoms equally distributed around the aglycone, and may retain the typical amphipathic features. On the other hand, escins without adjuvant activity have seven $\mathrm{O}$ atoms, with five localised around one side of the aglycone, thus reducing its hydrophobic and adjuvant nature.

As against the stimulatory effects on specific immunity components, saponins have also been shown to be able to prevent some non-specific immune reactions such as inflammation (de Oliveira et al. 2001; Haridas et al. 2001a) and monocyte proliferation (Delmas et al. 2000; Yui et al. 2001). Triterpenoid saponins from Acacia victoriae having $\alpha, \beta$ ester groups at $\mathrm{C}_{28}$ and the outer monoterpene chains could have reacted with cysteine residues in the nuclear transcription factor- $\kappa \mathrm{B}(\mathrm{NF}-\kappa \mathrm{B})$ molecule and this might have modified this molecule and prevented it from performing its normal function of stimulating genes involved in immune and inflammatory pathways in response to stress signals. One downstream effector substance whose activity has shown to be lowered by saponin is phospholipase $\mathrm{A}_{2}$ (see de Oliveira et al. 2001) that causes a decrease in hydrolysis in membrane phospholipids and thereby decreased membrane fluidity.

The varied action of saponins might indicate that the immunostimulatory effects of saponins are the result of specific targeting of physiological intermediaries rather than the result of a non-specific effect on cell membrane permeability.

\section{Cytostatic effects on malignant cells}

Saponins isolated from different plants and animals have been shown to specifically inhibit the growth of cancer cells in vitro (Kuznetzova et al. 1982; Rao \& Sung, 1995; Konoshima et al. 1998; Marino et al. 1998; Mimaki et al. 1998a; Podolak et al. 1998). The pursuit of natural substances capable of controlling malignancies has led to considerable research on this property of saponins. Kalopanaxsaponin A (often produced in the intestine from hederagenin glycosides by bacterial action) seems to be the basic saponin structure for cytotoxic activity (Park et al. 2001).

The depressive effect of saponins against cancer cells may take place through diverse and complex mechanisms. The destructive activity of saponins against cells such as erythrocytes was, however, not related to cytostatic activity against cancer cells (Mimaki et al. 1998b). Triterpenoid saponins (avicins from Acacia victoriae) selectively inhibited growth of tumour cell lines by cell cycle arrest in human breast cancer cell line and apoptosis in leukaemia cell line (Mujoo et al. 2001) and reduced both tumour incidence and multiplicity in a murine skin carcinogenesis model (Hanausek et al. 2001). Ginsenoside Rg3 was found to exert multiple anti-proliferative activity towards human prostate carcinoma cells including cell cycle arrest at G1 phase and stimulation of apoptosis. Saponin (triterpenoid or steroid)-induced apoptosis is primarily caused by stimulating the cytochrome $\mathrm{c}$-caspase 9 -caspase 3 pathway in the human cancer and other cell lines (Liu et al. 2000; Haridas et al. 2001b; Yui et al. 2001; Cai et al. 2002), a property that is shared by a ginseng saponin derivative (20-O( $\beta$-D-glucopyranosyl)-20(S)-protopanaxadiol) produced in 
the intestine by bacteria and absorbed into blood (Lee et al. 2000 c). Yui et al. (2001) detected specific toxic activity against macrophage colony-stimulating factor-induced growth of macrophages by terpenoids (securiosides) having specific structural features such as presence of dimethoxycinnamoyl group. Apoptosis seemed to be induced by mechanisms similar to those reported for Jurkat cells (Haridas et al. 2001b) here also, i.e. by stimulating the cytochrome $\mathrm{c}$-caspase pathway. Interestingly the securiosides seemed to have no or considerably weaker effects against other cells including thymocytes, bone marrow cells and tumour cell lines or even macrophages stimulated by growth factors other than macrophage colony-stimulating factor, revealing a high degree of structure-related specificity. Saponin-initiated cytotoxicity thus begins non-specifically with cell aggregation caused by detergent action (Mimaki et al. 2001), followed by specific toxicity determined by receptors on the cell surface and saponin structure leading to what seems to be a mechanism of apoptosis that is independent of saponin structure. The tumour-specificity of the cytotoxic action seems to be influenced by the structure of the sugar portion of the saponins (Kuroda et al. 2001) after the hydrophobic aglycone core allowed saponins to traverse the mitochondrial membrane. The mechanism of the cytochrome c release was, however, not caused by the anticipated passive permeabilisation of the mitochondrial membrane by saponin. A cell cycle arrest mediated by inhibition of the phosphatidylinositol-3-kinase-protein kinase signalling pathway (Mujoo et al. 2001) or direct suppression of protein kinase complex genes (Liu et al. 2000) is stimulated by saponins either along with the apoptotic pathway (Mujoo et al. 2001) or independently (Oh \& Sung, 2001), based on the structure of saponin. The complexity of effects and interactions involved could be seen from the fact that the ginsenosides $\mathrm{Rb}_{1}$ and $\mathrm{Rg}_{1}$ are able to inhibit apoptosis in a human neuroblastoma cell line induced by toxins (Rudakewich et al. 2001) and the abolishment by orally administered ginseng total saponins of morphine-induced apoptosis of thymocytes (Kim et al. 1999). The inhibition of the phosphatidylinositol-3-kinase-protein kinase pathway is considered important in apoptosis, given the role of protein kinases in inactivating the caspases (apoptotic enzymes). Avicins also decreased the release of reactive oxygen species from mitochondria, which along with the inhibition of reactive nitric oxide synthetase (Haridas et al. 2001b) might be the reason for the prevention of chromosomal damage reported in Hanausek et al. (2001). These activities may be considered as antioxidative in nature. But the above saponins lack an $\mathrm{H}$ atom-donating group and thus their effect must be at the physiological levels of specific induction. The following examples strengthen this observation. Saponins have been observed to decrease microsomal enzyme activity (Sindambiwe et al. 1998; Nguyen et al. 2000). Triterpenoid saponins from Acacia victoriae decreased expression of NF-кBregulated proteins such as inducible nitric oxide synthase and cyclo-oxygenase in human leukaemia cells in vitro, changes that may help prevent development of malignancies by reducing oxidative and nitrosative stress (Haridas et al. 2001a). Saponins also reduce occurrence of reactive oxygen species such as $\mathrm{H}_{2} \mathrm{O}_{2}$ (Haridas et al. 2001a; Pawar et al. 2001), probably by enhancing its breakdown by activation of peroxiredoxins and catalase, and/or glutathione peroxidase (see Deng \& Zhang, 1991) as well as by suppressing its production by inhibiting the phosphatidylinositol-3-kinase signalling pathway (Haridas et al. 2001a). Direct effects on genetic material have also been reported. Ginseng saponins have been found to be specific inducers of the superoxide dismutase gene, that codes for one of the major antioxidant enzymes, through transcription factor AP2 binding site and its induction (Kim et al. 1996).

Saponins might also exert an anti-cancer effect at the intestinal level. Bile acids are metabolised by intestinal microbes to form secondary bile acids that are implicated as causative agents of colon cancer. The binding of saponins to bile acids in the intestine could reduce the availability of bile acids to the microbial population, thus reducing the formation of carcinogenic substances in the colon (Cheeke, 1996). Saponin metabolites, for example the ginseoside metabolite M1 produced in the intestine by the action of microbes on ingested ginseng saponins, may also have anti-cancer effects (Wakabayashi et al. 1998). Hederagenin glycosides from Kalopanax pinctus could effectively prevent the metabolic activation of aflatoxin B-1 or scavenge the electrophilic intermediate capable of inducing mutation (Lee et al. 2000b). Theasaponin E-1 from seeds of the tea plant Camellia sinensis L. var. Assamica PIERRE exhibit considerable gastroprotective activity and the whole saponin fraction from teaseed protects gastric mucosal lesions induced by ethanol in rats (Murakami et al. 1999).

More clarity as to the structure-related specificity of saponins to different types of cancers would be desirable in designing therapeutic preparations. Interactions between saponins and carcinogens in the intestinal lumen also call for closer studies.

\section{Molluscicidal effect}

The molluscicidal properties of saponins were first observed by Lemma (1965) who noticed the toxic effects of extracts of unripe berries of Phytolacca dodecandra on river snails in Ethiopia. Efforts were then mounted to utilise this property of saponins to control diseases such as schistosomiasis, which are transmitted by molluscs. Saponins extracted from many other sources were also seen to have similar molluscicidal properties, for example purified Sesbania sesban saponins at 3-25 mg/kg (Dorsaz et al. 1988) and purified saponin mixtures from Maesa lanceolata at above 5 parts per million (Sindambiwe et al. 1998) have been found to be active against Biomphalaria glabrata. Monodesmodic triglycosides from the pericarp of the fruits of Sapindus rarak at $6.25-12.5 \mathrm{mg} / \mathrm{kg}$ (Hamburger et al. 1992), a spirostanol glycoside from the inflorescence of $Y$. aloifolia (Kishor \& Sati, 1990), and some 21,22 diacylated maesasaponins (Apers et al. 2000) were also molluscicides. The molluscicidal activity of the saponins may be due to their characteristic detergent effect on the soft body membranes of the molluscs. 


\section{Antifungal activity}

Saponins have high toxicity against fungi (Delmas et al. 2000; Wang et al. 2000a). Fungicidal activity against Trichoderma viride was previously used as an identification method for saponins. Kalopanaxsaponins A and I isolated from Kalopanax pinctus exhibited strong and specific antifungal activity against Candida albicans and Cryptococcus neoformans (Kim et al. 1998b). Asparagus saponin-1, from the lower leaves of Asparagus officinalis, has antifungal properties in concentrations of $0.5-8.0 \mu \mathrm{g} / \mathrm{ml}$ depending on the type of fungus (Shimoyamada et al. 1990). The monodesmosidic spirostanol saponins from $Y$. schidigera destroy certain food-deteriorating yeasts, film-forming yeasts, and dermatophytic yeasts and fungi (Miyakoshi et al. 2000). The major mechanism suggested for the antifungal activity of saponins is their interaction with membrane sterols. Synthetic steroid saponins prepared by Takechi et al. (1999) were both antifungal and haemolytic but in many cases haemolytic triterpenoid saponins show little antifungal activity. It was observed that those saponins having a branched-chain trisaccharide moiety without any oxygen-containing groups at $\mathrm{C}_{2}$ and $\mathrm{C}_{12}$ exhibited the anti-yeast activity, while saponins with $2 \beta$-hydroxyl or 12 keto groups showed very weak or no activity (Miyakoshi et al. 2000). A saponin with a disaccharide moiety exhibited relatively low activity and the aglycones or bidesmodic furostanol saponins showed no activity.

The antifungal activity of food-originated substances has attracted an applicational research. Some reports describe the anti-yeast activity of saponins as having an anti-food deteriorating effect (Miyakoshi et al. 2000).

\section{Virucidal activity}

Some saponins and sapogenins have been shown to be capable of deactivating viruses; for example, purified saponin mixture from Maesa lanceolata (Sindambiwe et al. 1998). Maesasaponins with 21,22 diacylation had virucidal activity (Apers et al. 2000). The triterpenoid sapogenin oleanolic acid inhibits HIV-1 virus replication probably by inhibiting HIV-1 protease activity (Mengoni et al. 2002).

\section{Effects on protozoa}

Saponins from different sources have been found to be detrimental to protozoa and have been identified as possible defaunating agents in the rumen (Wallace et al. 1994; Newbold et al. 1997). This property could be exploited in treatment of protozoal infections in other animals. Triterpenoid and steroid saponins have been found to be detrimental to several infectious protozoans such as Plasmodium falciparum (Traore et al. 2000), Giardia trophozoites (McAllister et al. 2001) and Leishmania species (Delmas et al. 2000; Plock et al. 2001). The toxicity of saponins to protozoans seems to be widespread and nonspecific and is obviously the result of their detergent effect on the cell membranes. The antiprotozoal property of saponins may be lost upon deglycosylation (Wang et al. 2000a).

\section{Antioxidant effects}

The importance of the antioxidants contained in foods is well appreciated for both preserving the foods themselves and supplying essential antioxidants in vivo. However, the term 'antioxidant' is very loosely used. Often, the term is used to describe chain-breaking inhibitors of lipid peroxidation as free radicals generated in vivo damage many targets other than lipids, including proteins, DNA and small molecules. These oxidation reactions might lead to an array of adverse biological effects. Some of the protection mechanisms afforded by saponins against this have already been discussed earlier. Twenty years ago Zilversmit (1979) hypothesised that atherogenesis might result from phenomena that occur immediately after eating, and that it might be affected by chylomicron remnants. Several researchers (Staprans et al. 1994; Wolff \& Nourooz-Zadeh, 1996; Ursini et al. 1998) expanded Zilversmit's hypothesis and suggested that dietary lipid hydroperoxides, which may be partly generated during digestion in the alkaline $\mathrm{pH}$ of the intestine, are the source of chylomicron remnants of lipid hydroperoxides, which are elevated in the postprandial state. These findings emphasise the importance of natural antioxidants in food, and throughout the digestive tract. Usually, polyphenols and carotenoid pigments, being the major nutritional antioxidants in food, attract most of the research in this area. Some saponins have also been found to have antioxidative or reductive activity.

A group of saponins produced in legumes, namely, group B soyasaponins, contain an antioxidant moiety attached at $C_{23}$ (Yoshiki et al. 1998). This unique sugar residue, 2, 3-dihydro-2, 5-dihydroxy-6-methyl-4H-pyran4-one (DDMP), allows saponins to scavenge superoxides by forming hydroperoxide intermediates, thus preventing bio-molecular damage by free radicals (Yoshiki \& Okubo, 1995; Hu et al. 2002). Previously it was suggested that the DDMP residue is lost during soyabean processing. However, it has been shown that soya ingredients (soyabean flour, toasted soya hypocotyls, soya protein isolates, textured vegetable protein, soya protein concentrates, and Novasoy) and soya foods (commercial soya milk, tofu, and tempeh) contain the group B soyasaponins from 0.20-114.02 $\mu \mathrm{mol} / \mathrm{g}$ (Hu et al. 2002). The DDMP moiety is widely distributed among legumes such as kidney beans, peanuts, chickpeas, clover, and Japanese bushclover (Yoshiki et al. 1998).

\section{Effects on nervous system functioning}

Ginseng extract has been shown to have neurotrophic and neuroprotective effects (Rudakewich et al. 2001). It significantly improves learning ability and cognitive functions in brain-damaged rats in a dose-dependent manner, and enhances the strategic performance of normal rats. These effects are thought to be due to membrane-stabilising effects such as the inhibition of $\mathrm{Na}^{+}$and $\mathrm{Ca}^{2+}$ channels (Zhao \& McDaniel, 1998). Ginseng total saponins injected intracerebroventricularly inhibit stress-induced hypothalamo-pituitary-adrenal responses by inducing NO production in the brain (Kim et al. 1998a). This may be 
beneficial in preventing the harmful effects of excessive increases in plasma corticosterone on the target organs under stressful circumstances.

Panax notoginseng saponins administered intraperitoneally significantly inhibited abnormal increases in platelet aggregation and platelet adhesiveness in rats subjected to permanent occlusion of the middle cerebral artery. Similar effects were observed with in vitro preparations. The anticerebral ischemic effect of Panax notoginseng saponins is probably due to changes in the rank and structure of functional membrane proteins induced by fluidity of membranes that lead to changes in protein activities (Ma \& Xiao, 1998). Platelet membrane glycoproteins play a key role in the adhesion of platelets to the walls of blood vessels, in the accretion of platelets and in the formation of thromboses.

Zhang et al. (2001) studied inhibition of gap junctionmediated intercellular communication (GJIC) by ginsenosides. Gap junctions are believed to be involved in the pathogenesis of many inherited and acquired human diseases. Some ginsenosides reduced GJIC by activating tyrosine kinase, while others produced the same effect by activating protein kinase $\mathrm{C}$. Tyrosine kinase and protein kinase $\mathrm{C}$ are the two primary kinases that phosphorylate connexins, leading to GJIC down regulation. Still other ginsenosides inhibited GJIC by directly modulating the gap junction channels. They were, for example, found to inhibit striatal dopamine release stimulated by psychostimulants (Shim et al. 2000) probably due to their effects on receptor-operated $\mathrm{Na}^{+}$channels in dopaminergic nerve terminals or on presynaptic nicotinic acetylcholine receptors. Even among the chemically related ginsenosides prominent structure-activity relationships were difficult to find, even among chemically-related ginsenosides.

\section{Glucocorticoid-like effects of saponins}

Lee et al. (1997) reported that the ginsenoside $\mathrm{Rg}_{1}$ suppressed growth in rat hepatoma cells through transactivation induced by its binding to the glucocorticoid receptor (GR). By using the antiglucocorticoid RU486 it was found that $\mathrm{Rg}_{1}$ induced gene expression through a GRmediated mechanism. This GR-mediated gene induction by $\mathrm{Rg}_{1}$ was coupled with other signalling pathways, as in the case of glucocorticoids, evidenced by synergistic induction in the presence of increasing doses of a cyclic adenosine monophosphate analogue (Chung et al. 1998). Again, $\operatorname{Rg}_{1}$ also caused a down regulation of GR in a manner similar to glucocorticoids. In contrast, chronic infusion of $\mathrm{Rg}_{1}$ restored binding capacity of type 1 corticosterone-preferring receptors in the hippocampal region of aged rats (de Kloet et al. 1987). Orally administered ginseng total saponins were shown to restore morphineinduced elevation of plasma corticosterone to the control level (Kim et al. 1999), probably through negative feedback exerted by ginseng saponin or metabolite-GR complexes. Other reports point out that saponin ingredients act by mechanisms other than binding to steroid receptors. Glycyrrhetinic acid, the active aglycone of a liquorice saponin, for example, was found to be a highly efficient inhibitor of corticosteroid 11ß-dehydrogenase (Monder et al. 1989) and showed mineralocorticoid-like activity. This enzyme catalyses the oxidation of the biologically active steroid cortisol to its inactive metabolite cortisone. (Glycyrrhizic acid and glycyrrhetinic acid glucuronide given orally to rats were reported to inhibit renal $11 \beta$ dehydrogenase in the Monder et al. (1989) study, providing further evidence of absorption of active saponin derivatives from the intestine.) Oral administration of saponins from Hernaria glabra, on the other hand, resulted in a significant decrease in blood pressure in hypertensive rats and increased salt and water transport in the renal tubules (Rhiouani et al. 1999).

The glucocorticoid-like action of saponins could possibly explain the diverse effects of saponins in biological systems. Glucocorticoids, acting through GR, are involved in the regulation of numerous physiological processes (Gagliardo et al. 2001). Upon ligand binding GR inhibits or stimulates gene transcription. On nuclear translocation GR transactivate DNA elements compatible with glucocorticoid response elements. Activated GR also antagonise transcription factors, particularly $\mathrm{NF}-\kappa \mathrm{B}$, directly and indirectly through gene transcription and protein synthesis of the NF- $\kappa$ B inhibitor (Almawi \& Melemedjian, 2002). $\mathrm{NF}-\kappa \mathrm{B}$ regulates a number of genes involved in immune and inflammatory pathways such as various pro-inflammatory cytokines, adhesion molecules, and apoptosis and has been shown to be affected by saponins (see Haridas et al. 2001a,b). Higher glucocorticoid activity has been described to have negative effects on female reproductive function (Andersen, 2002). Contradictory results are, however, common when the action of glucocorticoids is described, as several local mechanisms modulate its potency and availability at the tissue level. The end effects of glucocorticoid-like activity of saponins could hence be unpredictable and different from that of glucocorticoids itself as it is not known whether the modulatory machinery works in the same manner for saponins.

The action of saponins that evolved in plants as important defence adaptation against highly conserved key pathways such as the NF- $\mathrm{BB}$ pathway in potential rivals may also have evolutionary significance (Haridas et al. 2001a).

\section{Conclusions}

Saponin mixtures present in plants and plant products possess diverse biological effects when present in the animal body. With the information presently available, it is difficult to establish clear functionality and structureactivity relationships regarding the effects of saponins in biological systems. This is largely due to the occurrence of a vast number of saponins with similar chemical structures, and to the complexity of cellular physiological reactions, which are often differently influenced by small and subtle differences in stereo-structures of effector ligands. Other factors that could have substantial influence on saponin actions could be their interactions with other dietary constituents.

The membrane-permeabilising activity seems to be possessed by a large number of saponins, whether triterpenoid or steroid. The adjuvant effect of specific saponins and their derivatives on the specific immune system function 
have been proved in animal models. Saponins also show wide-ranging cytostatic effects against cancer cells. The ability of saponins to lower the serum cholesterol level of animals has also been reported. These favourable effects point to the potential of saponins, including those present in the diet, as a remedy against two of the major health hazards in many countries; obesity and cancer. Similarly, the sterol-mediated antiprotozoal and antifungal effects, and molluscicidal and antiviral effects, also offer considerable potential in managing various diseases. Other properties ascribed to saponins such as the beneficial effects that some of them are reported to have on the efficiency of feed utilisation and growth in ruminants, single-stomached animals and fish need further experimental proof to be conclusively established, and studies need to be directed towards understanding the factors, dietary- or animal- or saponin-related, for presence or absence of these beneficial effects. Another important area that calls for further investigation relates to the effects of saponins or their derivatives on animal and human reproductive cycles and hormonal balance. In view of their widespread presence in animal and human diets it would also be particularly interesting to further investigate the fate of saponins in the intestine of animals and their mechanisms of action at the intestinal and systemic levels.

Extensive in vivo studies are required using purified individual compounds and their well-defined derivatives (chemically altered or naturally occurring). Since the quantities available of such purified saponins are not large, small-animal models or fish could be used to understand structure-activity relationships or the mechanisms of their actions. Other problems worth keeping in mind are the changes in the nature and biological effects of the native compound taking place during the isolation and purification process. In addition, the saponins might produce the desired effects in conjuction or interacting with other moieties. Another approach, therefore, worth considering is the use of a well-defined saponin preparation (not necessarily structurally well-defined saponins) targeted at achieving the desired biological effects in a reproducible manner.

\section{References}

Abe H, Odashima S \& Arichi S (1978a) The effects of saikosaponins on biological membranes. 2. Changes in electron spin resonance spectra from spin labelled erythrocyte and erythrocyte ghost membranes. Planta Medica 34, 287-290.

Abe H, Sakaguchi M, Konishi H, Tani T \& Arichi S (1978b) The effects of saikosaponins on biological membranes. 1. The relationship between the structures of saikosaponins and haemolytic activity. Planta Medica 34, 160-166.

Al-Habori M \& Raman A (1998) Antidiabetic and hypocholesterolaemic effects of fenugreek (Review). Phytotherapy Research 12, 233-242.

Almawi WY \& Melemedjian OK (2002) Negative regulation of nuclear factor-kappa B activation and function by glucocorticoids. Journal of Molecular Endocrinology 28, 69-78.

Andersen CY (2002) Possible new mechanism of cortisol action in female reproductive organs: physiological implications of the free hormone hypothesis. Journal of Endocrinology 173 , 211-217.

Anderson DP (1992) Immunostimulants, adjuvants and vaccine carriers in fish: applications to aquaculture. Annual Review of Fish Diseases 2, 281-307.

Anthony NB, Balog JM, Staudinger FB, Wall CW, Walker RD \& Huff WE (1994) Effects of a urease inhibitor and ceiling fans on ascites in broilers. 1. Environmental variability and incidence of ascites. Poultry Science 73, 801-809.

Apers S, Baronikova S, Sindambiwe JB, Witvrouw M, De Clercq E, Vanden Berghe D, Van Marck E, Vlietinck A \& Pieters L (2000) Antiviral, haemolytic and molluscicidal activities of triterpenoid saponins from Maesa lanceolata: establishment of structure-activity relationships. Planta Medica 67, 528-532.

Arletti R, Benelli A, Cavazzuti E, Scarpetta G \& Bertolini A (1999) Stimulating property of Turnera diffusa and Pfaffia paniculata extracts on the sexual behavior of male rats. Psychopharmacology 143, 15-19.

Armah CN, Mackie AR, Roy C, Price K, Osbourn AE, Bowyer P \& Ladha $S$ (1999) The membrane-permeabilising effect of avenacin A-1 involves the reorganization of bilayer cholesterol. Biophysical Journal 76, 281-290.

Attele AS, Wu JA \& Yuan CS (1999) Ginseng pharmacology Multiple constituents and multiple actions. Biochemical Pharmacology 58, 1685-1693.

Authi KS, Rao GHR, Evenden BJ \& Crawford N (1988) Action of guanosine $5^{\prime}$-(beta-thio)diphosphate on thrombin-induced activation and calcium mobilization in saponin-permeabilized and intact human platelets. Biochemical Journal 255, 885-894.

Bae EA, Park SY \& Kim DH (2000) Constitutive beta-glucosidases hydrolyzing ginsenoside R-b1 and R-b2 from human intestinal bacteria. Biological and Pharmaceutical Bulletin 23, 1481-1485.

Bangham AD \& Horne RW (1962) Action of saponins on biological cell membranes. Nature 196, 952-953.

Barr IG, Sjolander A \& Cox JC (1998) ISCOMs and other saponin based adjuvants (Review). Advanced Drug Delivery Reviews 32, 247-271.

Bei L, Hu TH, Qian ZM \& Shen X (1998) Extracellular Ca2+ regulates the respiratory burst of human neutrophils. Biochimica et Biophysica Acta - Molecular Cell Research 1404, $475-483$.

Benie T, El-Izzi A, Tahiri C, Duval J \& Thieulant MLTI (1990) Combretodendron africanum bark extract as an antifertility agent. I: Estrogenic effects in vivo and LH release by cultured gonadotrope cells. Journal of Ethnopharmacology 29, 13-23.

Bloom BR (1989) Vaccines for the Third World. Nature 342, $115-116$.

Bomford R, Stapleton M, Winsor S, Beesley JE, Jessup EA, Price KR \& Fenwick GR (1992) Adjuvanticity and ISCOM formation by structurally diverse saponins. Vaccine 10, 572-577.

Bosler DA, Blümmel M, Bullerdieck P, Makkar HPS \& Becker K (1997) Influence of a saponin containing feed additive on mass development and carcass evaluation of growing lambs. Proceedings of the Society of Nutrition and Physiology 6, 46.

Brain K, Hadgraft J \& Al-Shatalebi M (1990) Membrane modification in activity of plant molluscicides. Planta Medica 56, 663.

Bureau DP, Harris AM \& Cho CY (1998) The effects of purified alcohol extracts from soy products on feed intake and growth of chinook salmon (Oncorhynchus tshawytscha) and rainbow trout (Oncorhynchus mykiss). Aquaculture 161, 27-43.

Cai J, Liu M, Wang Z \& Ju Y (2002) Apoptosis induced by dioscin in Hela cells. Biological and Pharmaceutical Bulletin 25, 193-196.

Calvert GD \& Blight L (1981) A trial of the effects of soya-bean 
flour and soya-bean saponins on plasma lipids, fecal bile acids and neutral sterols in hypercholesterlaemic men. British Journal of Nutrition 45, 277-281.

Chao AC, Nguyen JV, Broughall M, Recchia J, Kensil CR, Daddona PE \& Fix JA (1998) Enhancement of intestinal model compound transport by DS-1, a modified Quillaja saponin. Journal of Pharmaceutical Sciences 87, 1395-1399.

Chavali SR, Francis T \& Campbell JB (1987) An in vitro study of immunodilatory effects of some saponins. International Journal of Immunopharmacology 9, 675-683.

Cheeke PR (1996) Biological effects of feed and forage saponins and their impact on animal production. In Saponins Used in Food and Agriculture, pp. 377-386 [GR Waller and Y Yamasaki, editors]. New York: Plenum Press.

Chen JC \& Chen KW (1997) Oxygen uptake and ammonia-N excretion of juvenile Penaeus japonicus during depuration following one-day exposure to different concentrations of saponin at different salinity levels. Aquaculture 156, 77-83.

Chen JC, Xu MX, Chen LD, Chen YN \& Chiu TH (1998) Effect of Panax notoginseng saponins on sperm motility and progression in vitro. Phytomedicine 5, 289-292.

Choi S, Jung SY, Kim CH, Kim HS, Rhim H, Kim SC \& Nah SY (2001) Effect of Ginsenosides on voltage-dependent Ca2+ channel subtypes in bovine chromaffin cells. Journal of Ethnopharmacology 74, 75-81.

Chou SC, Ramanathan S, Matsui A, Rojers J \& Cutting WC (1971) Isolation of saponins with antifertility activity from Gleditschia horrida. Indian Journal of Experimental Biology 9, 503-504.

Chung E, Lee KY, Lee YJ, Lee YH \& Lee SK (1998) Ginsenoside $\mathrm{Rg} 1$ down-regulates glucocorticoid receptor and displays synergistic effects with cAMP. Steroids $\mathbf{6 3}, 421-424$.

Cossarni-Dunier M (1985) Effect of different adjuvants on the humoral immune response of rainbow trout. Developmental and Comparative Immunology 9, 141-146.

Coulter A, Wong TY, Drane D, Bates J, Macfarlan R \& Cox J (1998) Studies on experimental adjuvanted influenza vaccines: comparison of immune stimulating complexes (Iscoms (TM)) and oil-in-water vaccines. Vaccine 16, 1243-1253.

de Kloet ER, Reul JM, van den Bosch FR, Tonnaer JA \& Saito H (1987) Ginsenoside RG1 and corticosteroid receptors in rat brain. Endocrinology Japan 34, 213-220.

Delmas F, Di Giorgio C, Elias R, Gasquet M, Azas N, Mshvildadze V, Dekanosidze G, Kemertelidze E \& Timon-David P (2000) Antileishmanial activity of three saponins isolated from ivy, alpha-hederin, beta-hederin and hederacolchiside A(1), as compared with their action on mammalian cells cultured in vitro. Planta Medica 66, 343-347.

DeMeo MT, Mutlu EA, Keshavarzian A \& Tobin MC (2002) Intestinal Permeation and Gastrointestinal Disease. Journal of Clinical Gastroenterology 34, 385-396.

Deng HL \& Zhang JT (1991) Anti-lipid peroxilative effect of ginsenoside Rb1 and Rg1. Chinese Medical Journal 104, 395-398.

de Oliveira CAC, Perez AC, Merino G, Prieto JG \& Alvarez AI (2001) Protective effects of Panax ginseng on muscle injury and inflammation after eccentric exercise. Comparative Biochemistry and Physiology 130C, 369-377.

Dollahite JW, Shaver T \& Camp BJ (1962) Injected saponins as abortifacients. American Journal of Veterinary Research 23, $1261-1263$.

Dorsaz A-C, Hostettmann M \& Hostettmann K (1988) Molluscicidal saponins from Sesbania sesban. Planta Medica 54, 225-227.

El Izzi A, Benie T, Thieulant M-L, Le Men-Oliver L \& Duval J (1992) Stimulation of LH release from cultured pituitary cells by saponins of Petersianthus macrocarpus: a permeabilising effect. Planta Medica 58, 229-233.

El Izzi A, Duval J \& Delaude C (1989) Effet d'une serie de saponines extrites de vegetaux de L'Afrique tropicale sur la liberation d'hormone luteinisante par les cellules hypophysaires en culture (Effect of a series of saponin extracts from African plants on the release of luteinizing hormone by hypophysial cells in culture). Bulletin de la Societé Royale des Sciences de Liege 58, 53-56.

Enomoto Y, Ito K, Kawagoe Y, Morio Y \& Yamasaki Y (1986) Positive inotropic action of saponins on isolated atrial and papillary muscles from the guinea pig. British Journal of Pharmacology 88, 259-267.

Fenwick GR, Price KR, Tsukamoto C \& Okubo K (1991) Saponins. In Saponins in Toxic Substances in Crop Plants, [FJP D'Mello, CM Duffus and JH Duffus, editors]. Cambridge: The Royal Society of Chemistry.

Flaoyen A, Wilkins AL, Deng D \& Brekke T (2001) Ovine metabolism of saponins: Evaluation of a method for estimating the ovine uptake of steroidal saponins from Narthecium ossifragum. Veterinary Research Communications 25, 225-238.

Francis G, Makkar HPS \& Becker K (2001a) Antinutritional factors present in plant-derived alternate fish feed ingredients and their effects in fish. Aquaculture 199, 197-227.

Francis G, Makkar HPS \& Becker K (2001b) Effects of Quillaja saponins on growth, metabolism, egg production, and muscle cholesterol in individually reared Nile tilapia (Oreochromis niloticus). Comparative Biochemistry and Physiology 129C, $105-114$.

Francis G, Makkar HPS \& Becker K (2002a) Dietary supplementation with a Quillaja saponin mixture improves growth performance and metabolic efficiency in common carp (Cyprinus carpio L). Aquaculture 203, 311-320.

Francis G, Makkar HPS \& Becker K (2002b) Effects of cyclic and regular feeding of Quillaja saponin supplemented diet on growth and metabolism of common carp (Cyprinus carpio L). Fish Physiology and Biochemistry 24, 343-350.

Fukuda K, Utsumi H, Shoji J \& Hamada A (1985) Saponins can cause the agglutination of phospholipid vesicles. Biochimica et Biophysica Acta 820, 199-206.

Gagliardo R, Vignola AM \& Mathieu M (2001) Is there a role for glucocorticoid receptor beta in asthma? Respiratory Research 2, $1-4$.

Gee JM \& Johnson IT (1988) Interactions between haemolytic saponins, bile salts and small intestinal mucosa in the rat. Journal of Nutrition 118, 1391-1397.

Gee JM, Price KR, Johnson IT \& Rhodes MJ (1998) The relationship between saponin structure and bioactivity - a preliminary study. In Cost 98, Effects of Antinutrients on the Nutritional Value of Legume Diets no. 4, pp. 8-14 [S Bardocz \& A Pusztai, editors]. Luxemburg: European Commission.

Gee JM, Price KR, Ridout CL, Johnson IT \& Fenwick GR (1989) Effects of some purified saponins on transmural potential difference in mammalian small intestine. Toxicology In Vitro 3, 85-90.

Gee JM, Price KR, Ridout CL, Wortley GM, Hurrell RF \& Johnson IT (1993) Saponins of quinoa (Chenopodium quinoa): Effects of processing on their abundance in quinoa products and their biological effects on intestinal mucosal tissue. Journal of the Science of Food and Agriculture 63, 201-209.

Gee JM, Wal JM, Miller K, Atkinson H, Grigoriadou F, Wijnands MVW, Penninks AH, Wortley G \& Johnson IT (1997) Effect of saponin on the transmucosal passage of $\beta$-lactoglobulin across the proximal small intestine of normal and $\beta$-lacoglobulin-sensitised rats. Toxicology 117, 219-228.

Gee JM, Wortley GM, Johnson IT, Price KR, Rutten AAJJL, Houben GF \& Penninks AH (1996) Effect of saponins and glycoalkaloids on the permeability and viability of mammalian intestinal cells and on the integrity of tissue preparations in vitro. Toxicology In Vitro 10, 117-128. 
Glauert AM, Dingle JT \& Lucy JA (1962) Action of saponin on biological membranes. Nature 196, 953-955.

Gögelein H \& Hüby A (1984) Interaction of saponin and digitonin with black lipid membranes and lipid monolayers. Biochimica et Biophysica Acta 773, 32-38.

Grayson TH, Williams RJ, Wrathmell AB, Munn CB \& Harris JE (1987) Effects of immunopotentiating agents on the immune response of rainbow trout, Salmo gairdneri Richardson, to ERM vaccine. Journal of Fish Biology 31, Suppl. A, 195-202.

Gus-Mayer S, Brunner H, Schneider-Poetsch HA \& Rudiger W (1994) Avenacosidase from oat: purification, sequence analysis and biochemical characterization of a new member of the BGA family of beta-glucosidases. Plant Molecular Biology 26, 909-921.

Hamburger M, Slacanin I, Hostettmann K, Dyatmiko W \& Sutarjadi (1992) Acetylated saponins with molluscicidal activity from Sapindus rarak: unambiguous structure determination by proton nuclear magnetic resonance and quantitative analysis. Phytochemical Analysis 3, 231-237.

Han LK, Xu BJ, Kimura Y, Zheng YN \& Okuda H (2000) Platycodi radix affects lipid metabolism in mice with high fat dietinduced obesity. Journal of Nutrition 130, 2760-2764.

Hanausek M, Ganesh P, Walaszek Z, Arntzen CJ, Slaga TJ \& Gutterman JU (2001) Avicins, a family of triterpenoid saponins from Acacia victoriae (Bentham), suppress H-ras mutations and aneuploidy in a murine skin carcinogenesis model. Proceedings of the National Academy of Sciences USA 98, 11551-11556.

Haralampidis K, Trojanowska M \& Osbourn AE (2002) Biosynthesis of triterpenoid saponins in plants. Advances in Biochemical Engineering/Biotechnology 75, 31-49.

Haridas V, Arntzen CJ \& Gutterman JU (2001a) Avicins, a family of triterpenoid saponins from Acacia victoriae (Bentham), inhibit activation of nuclear factor-kappa $\mathrm{B}$ by inhibiting both its nuclear localization and ability to bind DNA. Proceedings of the National Academy of Sciences USA 98, 11557-11562.

Haridas V, Higuchi M, Jayatilake GS, Bailey D, Mujoo K, Blake ME, Arntzen CJ \& Gutterman JU (2001b) Avicins: triterpenoid saponins from Acacia victoriae (Bentham) induce apoptosis by mitochondrial perturbation. Proceedings of the National Academy of Sciences USA 98, 5821-5826.

Harris WS, Dujovne CA, Windsor SL, Gerrond LLC, Newton FA \& Gelfand RA (1997) Inhibiting cholesterol absorption with CP-88,818 (beta-tigogenin cellobioside; tiqueside): Studies in normal and hyperlipidemic subjects. Journal of Cardiovascular Pharmacology 30, 55-60.

Harwood HJ Jr, Chandler CE, Pellarin LD, Bangerter FW, Wilkins RW, Long CA, Cosgrove PG, Malinow MR, Marcetta CA, Pettini JL, Savoy YE \& Mayne JT (1993) Pharmacologic consequences of cholesterol absorption inhibition: alteration in cholesterol metabolism and reduction in plasma cholesterol concentration induced by the synthetic saponin $\beta$-tigogenin cellobioside (CP-88818; tiqueside). Journal of Lipid Research 34 377-395.

Hu J, Lee SO, Hendrich S \& Murphy PA (2002) Quantification of the group B soyasaponins by high-performance liquid chromatography. Journal of Agricultural and Food Chemistry 50, 2587-2594.

Hu M, Konoki K \& Tachibana K (1996) Cholesterol-independent membrane disruption caused by triterpenoid saponins. Biochimica et Biophysica Acta - Lipid Metabolism 1299, $252-258$.

Hussain I \& Cheeke PR (1995) Effect of Yucca scidigera extract on rumen and blood profiles of steers fed concentrate- or roughage-based diets. Animal Feed Science and Technology 51, $231-242$.

Ikedo S, Shimoyamada M \& Watanabe K (1996) Interaction between bovine serum albumin and saponin as studied by heat stability and protease digestion. Journal of Agricultural and Food Chemistry 44, 792.

Ishaaya I, Birk Y, Bondi A \& Tencer Y (1969) Soyabean saponins. IX. Studies of their effect on birds, mammals and cold-blooded organisms. Journal of the Science of Food and Agriculture 20, 433-436.

Ishisaki S, Iwase M \& Tanaka M (1997) Enhancing effect of starfish Asterias amurensis saponin upon thermal aggregation of actomyosin from alleye pollack meat. Fisheries Science 63, $159-160$.

Jenkins KJ \& Atwal AS (1994) Effects of dietary saponins on fecal bile acids and neutral sterols, and availability of vitamins $\mathrm{A}$ and $\mathrm{E}$ in the chick. Journal of Nutritional Biochemistry 5, 134-138.

Jenkins PG, Harris JE \& Pulsford AL (1991) Enhanced enteric uptake of human gamma globulin by Quil-A saponin in Oreochromis mossambicus. Fish and Shellfish Immunology 1, 279-295.

Jie YH, Cammisuli S \& Baggiolini M (1984) Immunomodulatory effects of Panax ginseung C. A. MEYER in the mouse. Agents and Actions 15, 386-391.

Johnson IT, Gee JM, Price K, Curl C \& Fenwick GR (1986) Influence of saponins on gut permeability and active nutrient transport in vitro. Journal of Nutrition 116, 2270-2277.

Johnston NL, Quarles CL \& Fagerberg DJ (1982) Broiler performance with DSS40 Yucca saponin in combination with monensin. Poultry Science 61, 1052-1054.

Johnston NL, Quarles CL, Fagerberg DJ \& Caveny DD (1981) Evaluation of Yucca saponin on broiler performance and ammonia suppression. Poultry Science 60, 2289-2292.

Kai L, Wang ZF \& Xiao JS (1998) L-type calcium channel blockade mechanisms of panaxadiol saponins against anoxic damage of cerebral cortical neurons isolated from rats. Acta Pharmacologica Sinica 19, 455-458.

Kensil CR (1996) Saponins as vaccine adjuvants. Critical Reviews in Therapeutic Drug Carrier Systems 13, 1-55.

Killeen GF, Madigan CA, Connolly CR, Walsh GA, Clark C, Hynes MJ, Timmins BF, James P, Headon DR \& Power RF (1998) Antimicrobial saponins of Yucca Schidigera and the implications of their in vitro properties for their in vivo impact. Journal of Agricultural and Food Chemistry 46, $3178-3186$.

Kim DH, Jung JS, Suh HW, Huh SO, Min SK, Son BK, Park JH, Kim ND, Kim YH \& Song DK (1998a) Inhibition of stressinduced plasma corticosterone levels by Ginsenosides in mice: involvement of nitric oxide. Neuroreport 9, 2261-2264.

Kim DW, Bang KH, Rhee YH, Lee KT \& Park HJ (1998b) Growth inhibitory activities of kalopanaxsaponins A and I against human pathogenic fungi. Archives of Pharmacal Research 21, 688-691.

Kim SJ, Kim YY, Ko KH, Hong EK, Han YB, Kang BH \& Kim $\mathrm{H}(1998 c)$ Butanol extract of $1: 1$ mixture of Phellodendron cortex and Aralia cortex stimulates PI3-kinase and ERK2 with increase of glycogen levels in HepG2 cells. Phytotherapy Research 12, 255-260.

Kim YH, Park KH \& Rho HM (1996) Transcriptional activation of the $\mathrm{Cu}, \mathrm{Zn}$-superoxide dismutase gene through the AP2 site by ginsenoside $\mathrm{Rb} 2$ extracted from a medicinal plant, Panax ginseng. Journal of Biological Chemistry 271, 24539-24543.

Kim YR, Lee SY, Shin BA \& Kim KM (1999) Panax ginseng blocks morphine-induced thymic apoptosis by lowering plasma corticosterone level. General Pharmacology 32, 647-652.

Kishor N \& Sati OP (1990) A new molluscicidal spirostanol glycoside of Yucca alufolia. Journal of Natural Products 53, $1557-1559$.

Klita PT, Mathison GW \& Fenton TW (1996) Effect of alfalfa 
root saponins on digestive function in sheep. Journal of Animal Science 74, 1144-1156.

Konoshima T, Takasaki M, Tokuda H, Nishino H, Duc NM, Kasai R \& Yamasaki K (1998) Anti-tumor-promoting activity of majonoside-R2 from Vietnamese ginseng, Panax vietnamensis HA et GRUSHV. (I). Biological and Pharmaceutical Bulletin 21, 834-838.

Krogdahl A, Roem A \& Baeverfjord G (1995) Effects of soybean saponin, raffinose and soybean alcohol extract on nutrient digestibilities, growth and intestinal morphology in Atlantic salmon. In Quality in Aquaculture. Proceedings of the International Conference of Aquaculture '95 and the Satellite Meeting Nutrition and Feeding of Cold Water Species, Trondheim, Norway, 9-12 August 1995. European Aquaculture Society Special Publication no 23, pp. 118-119 [N Svennevig and A Krogdahl, editors]. Gent, Belgium: European Aquaculture Society.

Kuroda M, Mimaki Y, Hasegawa F, Yokosuka A, Sashida Y \& Sakagami H (2001) Steroidal glycosides from the bulbs of Camassia leichtlinii and their cytotoxic activities. Chemical and Pharmaceutical Bulletin 49, 726-731.

Kuznetzova TA, Anisimov MM \& Popov AM (1982) A comparative study in vitro of physiological activity of triterpene glycosides of marine invertebrates of echinoderm type. Comparative Biochemistry and Physiology 73C, 41-43.

Lacaille-Dubois MA, Hanquet B, Cui ZH, Lou ZC \& Wagner H (1999) A new biologically active acylated triterpene saponin from Silene fortunei. Journal of Natural Products 62, 133-136.

Lee YJ, Chung E, Lee KY, Lee YH, Huh B \& Lee SK (1997) Ginsenoside-Rg1, one of the major active molecules from Panax ginseng, is a functional ligand of glucocorticoid receptor. Molecular and Cellular Endocrinology 133, 135-140.

Lee KT, Sohn IC, Kim DH, Choi JW \& Kwon SH (2000a) Hypoglycaemic and hypolipidemic effects of tectorigenin and kaikasaponin III in the streptozotocin-induced diabetic rat and their antioxidant activity in vitro. Archives of Pharmacal Research 23, 461-466.

Lee KT, Sohn IC, Park HJ, Kim DW \& Jung GO (2000b) Essential moiety for antimutagenic and cytotoxic activity of hederagenin monodesmosides and bisdesmosides isolated from the stem bark of Kalopanax pictus. Planta Medica 66, $329-332$.

Lee SJ, Ko WG, Kim JH, Sung JH, Lee SJ, Moon CK \& Lee BH $(2000 c)$ Induction of apoptosis by a novel intestinal metabolite of ginseng saponin via cytochrome c-mediated activation of caspase-3 protease. Biochemical Pharmacology 60, 677-685.

Lee SJ, Son KH, Chang HW, Kang SS \& Kim HP (1998) Antiinflammatory activity of Lonicera japonica. Phytotherapy Research 12, 445-447.

Lemma A (1965) A preliminary report on the molluscicidal property of endod (Phytolacca dodecandra). Ethiopian Medical Journal 3, 187.

Liu WK, Xu SX \& Che CT (2000) Anti-proliferative effect of ginseng saponins on human prostate cancer cell line. Life Sciences 67, 1297-1306.

Lu CD \& Jorgensen NA (1987) Alfalfa saponins affect site and extent of nutrient digestion in ruminants. Journal of Nutrition 117, 919-927.

Ma LY \& Xiao PG (1998) Effects of Panax notoginseng saponins on platelet aggregation in rats with middle cerebral artery occlusion or in vitro and on lipid fluidity of platelet membrane. Phytotherapy Research 12, 138-140.

McAllister TA, Annett CB, Cockwill CL, Olson ME, Wang Y \& Cheeke PR (2001) Studies on the use of Yucca schidigera to control giardiosis. Veterinary Parasitology 97, 85-99.

McGhee JR, Mestecky J, Dertzbaugh MT, Eldridge JH, Hirasawa M \& Kiyono H (1992) The mucosal immune system: from fundamental concepts to vaccine development. Vaccine 10, $75-88$.

McManus OB, Harris GH \& Giangiacombo KM (1993) An activator of calcium-dependent potassium channels isolated from a medicinal herb. Biochemistry 32, 6128-6133.

Mader TL \& Brumm MC (1987) Effect of feeding sarsasaponin in cattle and swine diets. Journal of Animal Science 65, 9-15.

Maharaj K, Froh KH \& Campbell JB (1986) Immune responses of mice to inactivated rabies vaccine administered orally: potentiation by Quillaja saponin. Canadian Journal of Microbiology 32, 414-420.

Makkar HPS, Aregheore EM \& Becker K (1999) Effects of saponins and plant extracts containing saponins on the recovery of ammonia during urea ammoniation of wheat straw and fermentation kinetics of the treated straw. Journal of Agricultural Science, Cambridge 132, 313-321.

Makkar HPS \& Becker K (1996) Effect of Quillaja saponins on in vitro rumen fermentation. In Saponins Used in Food and Agriculture, pp. 377-386 [GR Waller and Y Yamasaki, editors]. New York: Plenum Press.

Marino SD, Iorizzi M, Palagiano E, Zollo F \& Roussakis C (1998) Starfish saponins. 55. Isolation, structure elucidation, and biological activity of steroid oligoglycosides from an antarctic starfish of the family Asteriidae. Journal of Natural Products 61, 1319-1327.

Marston A, Wolfender JL \& Hostettmann K (2000) Analysis and isolation of saponins from plant material. In Saponins in Food, Feedstuffs and Medicinal Plants, Annual Proceedings of the Phytochemical Society, pp. 1-12 [W Oleszek and A Marston, editors]. Oxford and London: Clarendon Press.

Matsuda H, Li Y, Yamahara J \& Yoshikawa M (1999a) Inhibition of gastric emptying by triterpene saponin, momordin Ic, in mice: Roles of blood glucose, capsaicin-sensitive sensory nerves, and central nervous system. Journal of Pharmacology and Experimental Therapeutics 289, 729-734.

Matsuda H, Li YH, Murakami T, Yamahara J \& Yoshikawa M (1999b) Structure-related inhibitory activity of oleanolic acid glycosides on gastric emptying in mice. Bioorganic and Medicinal Chemistry 7, 323-327.

Matsuda H, Murakami K, Ninomiya K, Yamahara J \& Yoshikawa M (1997) Effects of escins 1a, 1b, 11a, and 11b from horse chestnut, the seeds of Aesculus hippocastanum L, on acute inflammation in animals. Chemical and Pharmaceutical Bulletin 20, 1092-1095.

Matsuura M (2001) Saponins in garlic as modifiers of the risk of cardiovascular disease. Journal of Nutrition 131, $1000 \mathrm{~S}-1005 \mathrm{~S}$.

Meagher LP, Smith BL \& Wilkins AL (2001) Metabolism of diosgenin-derived saponins: implications for hepatogenous photosensitization diseases in ruminants. Animal Feed Science and Technology 91, 157-170.

Melzig MF, Bader G \& Loose R (2001) Investigations of the mechanism of membrane activity of selected triterpenoid saponins. Planta Medica 67, 43-48.

Mengoni F, Lichtner M, Battinelli L, Marzi M, Mastroianni CM, Vullo V \& Mazzanti G (2002) In vitro anti-HIV activity of oleanolic acid on infected human mononuclear cells. Planta Medica 68, 111-114.

Menin L, Panchichkina M, Keriel C, Olivares J, Braun U, Seppert EK \& Saks VA (2001) Macrocompartmentation of total creatine in cardiomyocytes revisited. Molecular and Cellular Biochemistry 220, 149-159.

Menzies GS, Howland K, Rae MT \& Bramley TA (1999) Stimulation of specific binding of $[3 \mathrm{H}]$-progesterone to bovine luteal cell-surface membranes: specificity of digitonin. Molecular and Cellular Endocrinology 153, 57-69.

Mimaki Y, Kuroda M, Kameyama A, Yokosuka A \& Sashida Y 
(1998a) Steroidal saponins from the underground parts of Ruscus aculeatus and their cytostatic activity on HL-60 cells. Phytochemistry 48, 485-493.

Mimaki Y, Kuroda M, Kameyama A, Yokosuka A \& Sashida Y (1998b) Steroidal saponins from the rhizomes of Hosta sieboldii and their cytostatic activity on HL-60 cells. Phytochemistry 48, 1361-1369.

Mimaki Y, Yokosuka A, Kuroda M \& Sashida Y (2001) Cytotoxic activities and structure-cytotoxic relationships of steroidal saponins. Biological and Pharmaceutical Bulletin 24, $1286-1289$.

Miyakoshi M, Tamura Y, Masuda H, Mizutani K, Tanaka O, Ikeda T, Ohtani K, Kasai R \& Yamasaki K (2000) Antiyeast steroidal saponins from Yucca schidigera (Mohave yucca), a new anti-food-deteriorating agent. Journal of Natural Products 63, 332-338.

Monder C, Stewart PM, Lakshmi V, Valentino R, Burt D \& Edwards CRW (1989) Licorice inhibits corticosteroid 11ßdehydrogenase of rat kidney and liver: in vivo and in vitro studies. Endocrinology 125, 1046-1053.

Morehouse LA, Bangerter FW, DeNinno MP, Inskeep PB, McCarthy PA, Pettini JL, Savoy YE, Sugarman ED, Wilkins RW, Wilson TC, Woody HA, Zaccaro LM \& Chandler CE (1999) Comparison of synthetic saponin cholesterol absorption inhibitors in rabbits: evidence for a non-stoichiometric, intestinal mechanism of action. Journal of Lipid Research 40, 464-474.

Morrissey JP \& Osbourn AE (1999) Fungal resistance to plant antibiotics as a mechanism of pathogenesis. Microbiological and Molecular Biological Reviews 63, 708-724.

Mowat AM, Smith RE, Donachie AM, Furrie E, Grdic D \& Lycke N (1999) Oral vaccination with immune stimulating complexes. Immunology Letters 65, 133-140.

Muir AD, Ballantyne KD \& Hall TW (2000) LC-MS and LC-MS/ MS analysis of saponins and sapogenins - comparison of ionization techniques and their usefulness in compound identification. In Saponins in Food, Feedstuffs and Medicinal Plants, Annual Proceedings of the Phytochemical Society, pp. 35-42 [W Oleszek and A Marston, editors]. Oxford and London: Clarendon Press.

Mujoo K, Haridas V, Hoffmann JJ, Wachter GA, Hutter LK, Lu Y, Blake ME, Jayatilake GS, Bailey D, Mills GB \& Gutterman JU (2001) Triterpenoid saponins from Acacia victoriae (Bentham) decrease tumor cell proliferation and induce apoptosis. Cancer Research 61, 5486-5490.

Murakami T, Nakamura J, Matsuda H \& Yoshikawa M (1999) Bioactive saponins and glycosides. XV. Saponin constituents with gastroprotective effect from the seeds of tea plant, Camellia sinensis L var. assamica Pierre, cultivated in Sri Lanka: Structures of assamsaponins A, B, C, D, and E. Chemical and Pharmaceutical Bulletin 47, 1759-1764.

Namba T, Yoshsaki M, Tomimori T, Kobashi K, Mitsui K \& Hase J (1973) Haemolytic and protective activity of ginseng saponins. Chemical and Pharmaceutical Bulletin 21, 459-461.

Newbold CJ, El Hassan SM, Wang J, Ortega ME \& Wallace RJ (1997) Influence of foliage from African multipurpose trees on activity of rumen protozoa and bacteria. British Journal of Nutrition 78, 237-249.

Nguyen TD, Villard PH, Barlatier A, Elsisi AE, Jouve E, Duc NM, Sauze C, Durand A \& Lacarelle B (2000) Panax vietnamensis protects mice against carbon tetrachloride-induced hepatotoxicity without any modification of CYP2E1 gene expression. Planta Medica 66, 714-719.

Oakenfull DG (1986) Aggregation of bile acids and saponins in aqueous solution. Australian Journal of Chemistry 39, $1671-1683$.

Oakenfull DG \& Sidhu GS (1990) Could saponins be a useful treatment for hypercholesterolemia? European Journal of Clinical Nutrition 44, 79-88.

Oda K, Matsuda H, Murakami T, Katayama S, Ohgitani T \& Yoshikawa M (2000) Adjuvant and haemolytic activities of 47 saponins derived from medicinal and food plants. Biological Chemistry 381, 67-74.

Odenyo AA, Osuji PO \& Karanfil O (1997) Effects of multipurpose tree (MPT) supplements on ruminant ciliate protozoa. Animal Feed Science and Technology 67, 169-180.

Oh YJ \& Sung MK (2001) Soybean saponins inhibit cell proliferation by suppressing PKC activation and induce differentiation of HT-29 human colon adenocarcinoma cells. Nutrition and Cancer 39, 132-138.

Ohana P, Delmer DP, Carlson RW, Glushka J, Azadi P, Bacic T \& Benziman M (1998) Identification of a novel triterpenoid saponin from Pisum sativum as a specific inhibitor of the diguanylate cyclase of Acetobacter xylinum. Plant and Cell Physiolology 39, 144-152.

Oleszek W, Nowacka J, Gee JM, Wortley G \& Johnson IT (1994) Effects of some purified alfalfa (Medicago sativa) saponins on transmural potential difference in mammalian small intestine. Journal of the Science of Food and Agriculture 65, 35-39.

Onning G, Wang Q, Westrom BR, Asp NG \& Karlsson SW (1996) Influence of oat saponins on intestinal permeability in vitro and in vivo in the rat. British Journal of Nutrition 76, $141-151$.

Park HJ, Kwon SH, Lee JH, Lee KH, Miyamoto K \& Lee KT (2001) Kalopanaxsaponin A is a basic saponin structure for the anti-tumor activity of hederagenin monodesmosides. Planta Medica 67, 118-121.

Pawar R, Gopalakrishnan C \& Bhutani KK (2001) Dammarane triterpene saponin from Bacopa monniera as the superoxide inhibitor in polymorphonuclear cells. Planta Medica 67, $752-754$.

Petit PR, Sauvaire Y, Ponsin G, Manteghetti M, Fave A \& Ribes G (1993) Effects of a fenugreek seed extract on feeding behaviour in the rat: metabolic endocrine correlates. Pharmacology Biochemistry and Behaviour 45, 369-374.

Petit PR, Sauvaire YD, Hillairebuys DM, Leconte OM, Baissac YG, Ponsin GR \& Ribes GR (1995) Steroid saponins from fenugreek seeds - extraction, purification, and pharmacological investigation on feeding behavior and plasma cholesterol. Steroids 60, 674-680.

Pillion DJ, Amsden JA, Kensil CR \& Recchia J (1996) StructureFunction relationship among Quillaja saponins serving as excipients for nasal and ocular delivery of insulin. Journal of Pharmaceutical Sciences 85, 518-524.

Plock A, Sokolowska-Kohler W \& Presber W (2001) Application of flow cytometry and microscopical methods to characterize the effect of herbal drugs on Leishmania spp. Experimental Parasitology 97, 141-153.

Plohmann B, Bader G, Hiller K \& Franz G (1997) Immunomodulatory and antitumoral effects of triterpenoid saponins. Pharmazie 52, 953-957.

Podolak I, Elas M \& Cieszka K (1998) In vitro antifungal and cytotoxic activity of triterpene saponosides and quinoid pigments from Lysimachia vulgaris L. Phytotherapy Research 12, S70-S73.

Potter SM, Jimenez-Flores R, Pollack J, Lone TA \& Berber-Jimenez MD (1993) Protein saponin interaction and its influence on blood lipids. Journal of Agricultural and Food Chemistry 41, $1287-1291$.

Price KR, Morgan C, Gee JM, Wortley G, Johnson IT \& Fenwick GR (1994) Structure activity relationships for saponins and gut permeability, In Proceedings of the International Euro Food TOX IV Conference 'Bioactive substances in food of plant origin', 1994, vol. 2, pp. 382-385. Olsztyn, Poland: Polish 
Academy of Sciences, Centre for Agrotechnology and Veterinary Sciences.

Punnonen R \& Lukola A (1980) Oestrogen-like effect of ginseng. British Medical Journal 281, 1110.

Quin G-W \& Xu R-S (1998) Recent advances in bioactive natural products from Chinese medicinal plants. Medical Research Reviews 18, 375-382.

Rao AV \& Sung M-K (1995) Saponins as anticarcinogens. Journal of Nutrition 125, 717S-724S.

Recchia J, Lurantos MHA, Amsden JA, Storey J \& Kensil CR (1995) A semisynthetic Quillaja saponin as a drug delivery agent for aminoglycosaide antibiotics. Pharmaceutical Research 12, 1917-1923.

Rhiouani H, Settaf A, Lyoussi B, Cherrah Y \& Lacaille-Dubois A (1999) Effects of saponins from Herniaria glabra on blood pressure and renal function in spontaneously hypertensive rats. Therapie 54, 735-739.

Riguera R (1997) Isolating bioactive compounds from marine organisms. Journal of Marine Biotechnology 5, 187-193.

Ronnberg B, Fekadu M, Behboudi S, Kenne L \& Morein B (1997) Effects of carbohydrate modification of Quillaja saponaria Molina QH-B fraction on adjuvant activity, cholesterolbinding capacity and toxicity. Vaccine 15, 1820-1826.

Roy PK \& Munshi JD (1989) Effect of saponin extracts on oxygen uptake and haematology of an air-breathing climbing perch, Anabas testudineus (Bloch). Journal of Freshwater Biology 1, 167-172.

Roy PK, Munshi JD \& Dutta HM (1990) Effect of saponin extracts on morpho-history and respiratory physiology of an air breathing fish, Heteropneustes fossilis (Bloch). Journal of Freshwater Biology 2, 135-145.

Rudakewich M, Ba F \& Benishin CG (2001) Neurotrophic and neuroprotective actions of Ginsenosides $\mathrm{Rb}(1)$ and $\operatorname{Rg}(1)$. Planta Medica 67, 533-537.

Santos WR, Bernardo RR, Pecanha LMT, Palatnic M, Parente JP $\&$ de Sousa CB (1997) Haemolytic activities of plant saponins and adjuvants. Effect of Periandra mediterranea saponin on the humoral response to the FML antigen of Leishmania donovani. Vaccine 15, 1024-1029.

Sasaki S, Sumino K, Hamajima K, Fukushima J, Ishii N, Kawamoto S, Mohri H, Kensil CR \& Okuda K (1998) Induction of systemic and mucosal immune responses to human immunodeficiency virus type 1 by a DNA vaccine formulated with QS-21 saponin adjuvant via intramuscular and intranasal routes. Journal of Virology 72, 4931-4939.

Schopke T (2000) Non-NMR methods for structure elucidation of saponins. In Saponins in Food, Feedstuffs and Medicinal Plants, Annual Proceedings of the Phytochemical Society, pp. 106-113 [W Oleszek and A Marston, editors]. Oxford and London: Clarendon Press.

Seeman P (1974) Ultrastructure of membrane lesions in immune lysis, osmotic lysis and drug-induced lysis. Federation Proceedings 33, 2116-2124.

Seeman P, Cheng D \& Iles GH (1973) Structure of membrane holes in osmotic and saponin hemolysis. Journal of Cell Biology 56, 519-527.

Segal R, Shatkovsky P \& Milo-Goldzweig I (1974) On the mechanism of saponin hemolysis -1. Hydrolysis of the glycosidic bond. Biochemical Pharmacology 23, 973-981.

Sen S, Makkar HPS \& Becker K (1998) Alfalfa saponins and their implication in animal nutrition. Journal of Agricultural and Food Chemistry 46, 131-140.

Shim I, Javaid JI \& Kim SE (2000) Effect of ginseng total saponin on extracellular dopamine release elicited by local infusion of nicotine into the striatum of freely moving rats. Planta Medica 66, 705-708.

Shimoyamada M, Ikedo S, Ootsubo R \& Watanabe K (1998)
Effects of soybean saponins on chymotryptic hydrolyses of soybean proteins. Journal of Agricultural and Food Chemistry 46, 4793-4797.

Shimoyamada M, Suzuki M, Sonta H, Maruyama M \& Okubo K (1990) Antifungal activity of saponin fraction obtained from Asparagus Officinalis L. and its active principle. Agricultural and Biological Chemistry 54, 2553-2557.

Sim JS, Kitts WD \& Bragg DB (1984) Effect of dietary saponin on egg cholesterol level and laying hen performance. Canadian Journal of Animal Science 64, 977-984.

Sindambiwe JB, Calomme M, Geerts S, Pieters L, Vlietinck AJ \& Vanden Berghe DA (1998) Evaluation of biological activities of triterpenoid saponins from Maesa lanceolata. Journal of Natural Products 61, 585-590.

Sjolander A, Cox JC \& Barr IG (1998) ISCOMs: an adjuvant with multiple functions (Review). Journal of Leukocyte Biology 64, 713-723.

So HS, Yoon HS, Kwoon YS, Sung JH, Lee TG, Park EN, Cho HS, Lee BM, Cho JM \& Ryu WS (1997) Effect of a novel saponin adjuvant derived from Quillaja saponaria on immune response to recombinant hepatitis B surface antigen. Molecular Biology of Cells 7, 176-186.

Southon S, Johnson IT, Gee JM \& Price KR (1988) The effect of Gypsophylla saponins in the diet on mineral status and plasma cholesterol concentration in the rat. British Journal of Nutrition 59, 49-55.

Staprans I, Rapp JH, Pan XM, Kim KY \& Feingold KR (1994) Oxidized lipids in the diet are a source of oxidized lipid in chylomicrons of human serum. Arteriosclerosis and Thrombosis 14, 1900-1905.

Stark A \& Madar Z (1993) The effect of an ethanol extract derived from fenugreek (Trigonella foenum-graecum) on bile acid absorption and cholesterol level in rats. British Journal of Nutrition 69, 277-287.

Steurer S, Wurglics M, Likussar W, Burmistrov K, Michelitsch A \& Schubert-Zsilavecz M (1999) Lack of correlation between surface and interfacial activities of saponins and their haemolytic properties. Pharmazie 54, 766-767.

Stolzenberg SJ \& Parkhurst RM (1976) Blastocidal and contraceptive actions by an extract and compounds from endod (Phytolacca dodecandra). Contraception 14, 39-51.

Story JA, LePage SL \& Petro MS (1984) Interactions of alfalfa plant and sprout saponins with cholesterol in vitro and in cholesterol-fed rats. American Journal of Clinical Nutrition 39, 917-929.

Sugano M, Goto S, Yamada Y, Yoshido K, Hashimoto Y, Matsuo T \& Kimoto M (1990) Cholesterol lowering activity of various undigested fractions of soybean protein in rats. Journal of Nutrition 120, 977-985.

Takechi M, Matsunami S, Nishizawa J, Uno C \& Tanaka Y (1999) Haemolytic and antifungal activities of saponins or anti-ATPase and antiviral activities of cardiac glycosides. Planta Medica 65, 585-586.

Takechi M \& Tanaka Y (1995a) Structure-activity relationship of synthetic methyl urosylate glycosides. Phytochemistry 34, 675.

Takechi M \& Tanaka Y (1995b) Haemolytic and time course differences between steroid and triterpenoid saponins. Planta Medica 61, 76-77.

Tamura K, Honda H, Mimaki Y, Sashida Y \& Kogo H (1997) Inhibitory effects of a new steroidal saponin, OSW-1, on ovarian function in rats. British Journal of Pharmacology 121, 1796-1802.

Teferedegne B (2000) New perspectives on the use of tropical plants to improve ruminant nutrition. Proceedings of the Nutrition Society 59, 209-214.

Terapunduwat S \& Tasaki I (1986) Effect of dietary saponin on the performance and plasma cholesterol level of chicks and 
the alleviation of saponin toxicity by cholesterol supplementation. Japanese Journal of Zootechnical Science 57, 524-533.

Tewary PV, Chaturvedi C \& Pandey VB (1973) Antifertility activity of Costus speciosus Sm. Indian Journal of Pharmacology 35, 114-115.

Traore F, Faure R, Ollivier E, Gasquet M, Azas N, Debrauwer L, Keita A, Timon-David P \& Balansard G (2000) Structure and antiprotozoal activity of triterpenoid saponins from Glinus oppositifolius. Planta Medica 66, 368-371.

Ursini F, Zamburlini A, Cazzolato G, Maiorino M, Bon GB \& Sevanian A (1998) Postprandial plasma lipid hydroperoxides: a possible link between diet and atherosclerosis. Free Radical Biology and Medicine 25, 250-252.

Wakabayashi C, Hasegawa H, Murata J \& Saiki I (1997) In vivo antimetastatic action of ginseng protopanaxadiol saponins is based on their intestinal bacterial metabolites after oral administration. Oncology Research 9, 411-417.

Wakabayashi C, Murakami K, Hasegawa H, Murata J \& Saiki I (1998) An intestinal bacterial metabolite of ginseng protopanaxadiol saponins has the ability to induce apoptosis in tumor cells. Biochemical and Biophysical Research Communications 246, 725-730.

Wallace RJ, Arthaud L \& Newbold CJ (1994) Influence of Yucca shidigera extract on ruminal ammonia concentrations and ruminal microorganisms. Applied Environmental Microbiology 60, $1762-1767$.

Wang Y, McAllister TA, Yanke LJ \& Cheeke PR (2000a) Effect of steroidal saponin from Yucca schidigera extract on ruminal microbes. Journal of Applied Microbiology 88, 887-896.

Wang YX, McAllister TA, Yanke LJ, Xu ZJ, Cheeke PR \& Cheng KJ (2000b) In vitro effects of steroidal saponins from Yucca schidigera extract on rumen microbial protein synthesis and ruminal fermentation. Journal of the Science of Food and Agriculture 80, 2114-2122.

Woldemichael GM \& Wink M (2001) Identification and biological activities of triterpenoid saponins from Chenopodium quinoa. Journal of Agricultural and Food Chemistry 49, 2327-2332.

Wolff SP \& Nourooz-Zadeh J (1996) Hypothesis: UK consumption of dietary lipid hydroperoxides - a possible contributory factor to atherosclerosis. Atherosclerosis 119, 261-263.
World Health Organization (1996) The World Health Report. Geneva: WHO.

Wu Z, Sadik M \& Sleiman FT (1994) Influence of Yucca extract on ruminal metabolism in cows. Journal of Animal Science 72, $1038-1042$.

Yamasaki Y, Ito K, Enomoto Y \& Sutko JL (1987) Alterations by saponins of passive calcium permeability and sodium-calcium exchange activity of canine cardiac sarcolemnal vesicles. Biochimica et Biophysica Acta 897, 481-487.

Yoshikawa M, Murakami T, Kishi A, Kageura T \& Matsuda H (2001) Medicinal flowers. III. Marigold (1): hypoglycaemic, gastric emptying inhibitory, and gastroprotective principles and new oleanane-type triterpene oligoglycosides, calendasaponins A, B, C, and D, from Egyptian Calendula officinalis. Chemical and Pharmaceutical Bulletin 49, 863-870.

Yoshiki Y, Kudou S \& Okubo K (1998) Relationship between chemical structures and biological activities of triterpenoid saponins from soybean (Review). Bioscience Biotechnology and Biochemistry 62, 2291-2299.

Yoshiki Y \& Okubo K (1995) Active oxygen scavenging activity of DDMP (2,3-dihydro-2, 5-dihydroxy-6-methyl-4H-pyran-4one) saponin in soybean seed. Bioscience Biotechnology and Biochemistry 59, 1556-1557.

Yoshikoshi M, Kahara T, Yoshiki Y, Ito M, Furukawa Y, Okubo K \& Amarowicz R (1995) Metabolism and nonabsorption of soybean hypocotyl saponins in the rat model. Acta Alimentaria 24, 355-364.

Yui S, Ubukata K, Hodono K, Kitahara M, Mimaki Y, Kuroda M, Sashida Y \& Yamazaki M (2001) Macrophage-oriented cytotoxic activity of novel triterpene saponins extracted from roots of Securidaca inappendiculata. International Immunopharmacology 1, 1989-2000.

Zhang YW, Dou DQ, Zhang L, Chen YJ \& Yao XS (2001) Effects of Ginsenosides from Panax ginseng on cell-to-cell communication function mediated by gap junctions. Planta Medica 67, 417-422.

Zhao RZ \& McDaniel WF (1998) Ginseng improves strategic learning by normal and brain-damaged rats. NeuroReport $\mathbf{9}$, $1619-1624$.

Zilversmit DB (1979) Atherogenesis: a postprandial phenomenon. Circulation 60, 473-485. 